\title{
Desenvolvimento de biocompósitos de poli(L-ácido láctico) (PLLA) com serragem de madeira
}

\section{Development of poly(L-lactic acid) (PLLA) biocomposites with waste wood}

\author{
Schaiane Silveira Bitencourt ${ }^{1}$, Ketlin Cristina Batista ${ }^{2}$, \\ Ademir José Zattera ${ }^{3}$, Denise Abatti Kasper Silva ${ }^{4}$, \\ Ana Paula Testa Pezzin 5
}

\footnotetext{
1, 4, 5 Mestrado em Engenharia de Processos (MEP), Universidade da Região de Joinville (UNIVILLE). Rua Paulo Malschitzki 10. Zona Industrial.CEP:89.201-974, Joinville-SC, Brasil. e-mail: anapezzin@yahoo.com.br

${ }^{2}$ Departamento de Engenharia Ambiental e Sanitária, Universidade da Região de Joinville (UNIVILLE), Joinville, SC, Brasil.

${ }^{3}$ Programa de Pós-graduação em Engenharia de Processos e Tecnologias (PGPROTEC), Universidade de Caxias do Sul (UCS), Caxias do Sul, RS, Brasil.
}

\begin{abstract}
RESUMO
Os polímeros petroquímicos levam centenas anos para sofrerem decomposição, acarretando em acúmulo de resíduos nos lixões e aterros sanitários. Este impacto ambiental pode ser minimizado por meio do uso de polímeros biodegradáveis. Neste contexto, este trabalho buscou uma opção "ecologicamente amigável" para a substituição de polímeros sintéticos convencionais, por meio do estudo dos biocompósitos de poli(L - ácido láctico) (PLLA) com a incorporação de resíduos de madeira (RM) e de aditivos, visando desenvolver novos compósitos. Assim, foram processados três diferentes tipos de amostras por extrusão, seguida de injeção, os biocompósitos de PLLA com adição de RM (PLLA/RM), com adição de um agente de acoplamento, o difenil-isocianato (MDI) denominadas de PLLA/RM/MDI e com adição ainda de um agente lubrificante, o Struktol ${ }^{\circledR}$ (s), denominadas de PLLA/RM/MDI/s, contendo de 0 a $40 \%(\mathrm{~m} / \mathrm{m})$ de RM. As amostras foram caracterizadas por ensaio de resistência à tração, calorimetria exploratória diferencial (DSC), análise termogravimétrica (TGA), microscopia eletrônica de varredura (MEV), absorção de água, densidade, teor de vazios e espectroscopia no infravermelho com transformada de Fourier (FTIR). As amostras PLLA/RM/MDI/s foram também avaliadas quanto à biodegradação em solo. Os resultados revelaram que as amostras com MDI apresentaram melhores propriedades mecânicas, menor taxa de absorção de água, sem perda da estabilidade térmica, sugerindo que o MDI tenha promovido melhoria da adesão interfacial. Observou-se início do processo de biodegradação das amostras após 5 meses em solo, evidenciado por alterações visuais, bem como nas análises de TGA e DSC, sendo que o aumento do teor de RM acelerou o processo.
\end{abstract}

Palavras-chave: biocompósitos, PLLA, resíduos de madeira, MDI, Struktol ${ }^{\circledR}$

\section{ABSTRACT}

The petrochemical polymers take hundreds of years to decompose, resulting in accumulation of waste in dumps and landfills. The environmental impact can be minimized with the use of biodegradable polymers. In this context, this study sought an option "environmentally friendly" to replace conventional synthetic polymers through the study of biocomposites from poly(L - lactic acid) (PLLA) with the incorporation of wood waste (WW) and additives in order to develop new products. Thus, we processed three different types of samples by extrusion followed by injection of PLLA biocomposites with the addition of WW: (PLLA/WW) with addition of a coupling agent, the diphenyl isocyanate (MDI) called PLLA/WW/MDI and even with the addition of a lubricating agent, the Struktol® (s), called PLLA/WW/MDI/s containing from 0 to $40 \%$ wt of WW. The samples were characterized by tensile strength test, differential scanning calorimetry (DSC), thermogravimetric analysis (TGA), scanning electron microscopy (SEM), water absorption, density, void content and Fourier transformed infrared spectroscopy (FTIR). The samples PLLA/WW/MDI/s were also evaluated by biodegradation in soil. The results revealed that samples with MDI showed better mechanical properties, 
lower water absorption rate, without loss of thermal stability, suggesting that MDI has promoted improvement of interfacial adhesion. The start of biodegradation process of the samples was observed after 5 months in soil, as evidenced by visual changes, as well as the TGA and DSC analysis, and the increasing content of WW accelerated the process.

Keywords: biocomposites, PLLA, waste wood, isocyanate, Struktol ${ }^{\circledR}$

\section{INTRODUÇÃO}

O crescente interesse na utilização de polímeros biodegradáveis, principalmente os biopolímeros, está relacionado a muitos fatores, incluindo a demanda do consumidor por produtos mais sustentáveis e ambientalmente amigáveis, a preocupação com o acúmulo de resíduos sólidos, o desenvolvimento de polímeros que utilizem matérias-primas vegetais e o aumento, principalmente em países europeus, das restrições de uso de polímeros de origem petroquímica, particularmente em aplicações em setores de embalagens, automotivo e Indústria Elétrica e Eletrônica, etc [1-8].

Um relatório publicado pela BCC Research demonstra que o mercado de biopolímeros está crescendo a cada ano e novas exigências de aplicações devem oferecer benefícios claros aos clientes e meio ambiente. Para 2014, o relatório estimou, para aquele ano, uma demanda mundial de bioplásticos em mais de $1,4 \times 10^{9}$ $\mathrm{kg}$ e que esse deve aumentar até cerca de $6,0 \times 10^{9} \mathrm{~kg}$ em 2019, o que representa uma taxa de crescimento de $328 \%$ para o período de 2014 para 2019 [4].

A classificação em biopolímeros pode descrever uma série contínua de polímeros, que vão desde os que são obtidos a partir de matérias-primas renováveis anualmente, para aqueles que, em última instância se degradam em subprodutos não prejudiciais, após a sua vida útil [9]. O poli(L- ácido láctico) (PLLA) vem recebendo cada vez mais atenção de ambas as comunidades científicas e industriais, uma vez que atualmente tem o maior potencial comercial como um plástico versátil biodegradável feito a partir de materiais agrícolas renováveis, como milho ou batatas fermentados[10,11]. Com base na sua biodegradabilidade e biocompatibilidade, o poli(ácido láctico) (PLA) é amplamente utilizado na medicina, engenharia de tecidos e alguns outros campos da vida civil, como libertação controlada de fármacos, compostos implantáveis, dispositivos para fixação óssea, embalagens de papel, revestimentos, sistemas de libertação prolongada para pesticidas e fertilizantes e embalagens [12-14]. Entretanto, para setores como o de embalagem ou de engenharia, os biopolímeros não são totalmente competitivos com polímeros produzidos a partir dos commodites como por exemplo, poliestireno (PS), polietileno (PE), polipropileno (PP), poli(tereftalato de etileno) (PET), etc [15].

De modo geral, os PLAs possuem boas propriedades mecânicas (em particular, elevada resistência à tração e módulo de elasticidade, boa resistência à flexão) [16], quando comparados ao PS, PP, PE e alguns outros polímeros. A resistência à tração e módulo de elasticidade dos PLAs são comparáveis aos do PET, mas infelizmente o PLLA é muito quebradiço, com menos do que $10 \%$ de alongamento na ruptura e baixa tenacidade, o que limita o seu uso em aplicações que necessitam de deformação plástica sob grande tensões [17]. Para aplicações em embalagem, afirma-se que as películas de PLLA tenham propriedades mecânicas comparáveis às do PET, sua temperatura de transição vítrea inferior é considerada uma desvantagem, especialmente em aplicações como embalagem a quente, e que exige resistência a altas temperaturas [18]. Diferentes estratégias têm sido desenvolvidas para alterar as propriedades mecânicas de PLLA, dentre elas a proposição de diferentes compósitos aplicando fibras naturais ou artificiais, tais como cânhamo, linho, kenaf, fibra de vidro e fibra de carbono para reforço PLLA [19]. Dentre alguns exemplos de aplicações de fibras naturais em biocompósitos de matriz PLLA com sementes de Cuphea e lasquerella visando desenvolver compósitos poliméricos verdes com propriedades mecânicas adequadas para materiais de construção leves ou painéis interiores automotivos [20]. A utilização de fibras de cânhamo em PLLA aumentou a resistência à tração e ao impacto e o módulo de flexão devido à boa compatibilidade entre as fibras de cânhamo e o PLLA [21]. O emprego de fibras de linho com PLLA via extrusão foi considerado um reforço mecânico promissor, principalmente quando triacetina foi incorporada como agente compatibilizante [22]. No estudo de compósitos PLLA/fibras de kenaf, utilizados para produtos eletrônicos, descobriu-se que a adição desta fibra na matriz PLLA aumentou a resistência ao calor, o módulo de elasticidade e melhorou o processo de moldagem do material [23].

Dentre os resíduos celulósicos de conhecida aplicação em compósitos poliméricos, estão os resíduos de madeira, formando a chamada madeira plástica que vem obtendo grande aceitação pelo mercado global devido às suas características como: redução de custos e da massa, propriedades superiores em relação à madeira e ao polímero separadamente e acima de tudo, a motivação das indústrias pelo reaproveitamento do subproduto criando uma expectativa futura de aplicação de polímeros ambientalmente amigáveis [24].

A geração de resíduos de madeira e derivados da indústria moveleira é variável, depende dos métodos de produção e nem sempre têm uma destinação adequada. O potencial de aproveitamento destes resíduos é significativo, quer seja como matéria-prima secundária, quer seja pelo seu potencial energético [25]. 
Analisando esses resíduos gerados pelo processo produtivo como, cascas, costaneiras, aparas e serragem, seria irracional não promover o aproveitamento máximo destes subprodutos oriundos do beneficiamento primário da madeira. Tais resíduos, em primeiro momento são tidos como rejeitos no processo, mas podem sair da serraria como matéria-prima para produção de pasta e celulose, de chapas e compostos orgânicos, bem como promover a autossuficiência energética da própria indústria [26]. Assim, a inclusão de cargas, como o resíduo proveniente da indústria moveleira, é uma alternativa que agrega valor ao PLLA, tornando-o mais acessível ao mercado, aliada à vantagem da completa biodegradação [27, 28].

Em se tratando de compósitos, vários métodos foram investigados para melhorar a adesão entre a carga/reforço vegetal e a matriz de termoplásticos, por se saber que o desempenho do material final está relacionado à essa adesão. Dentre os compatibilizantes mais comuns está o anidrido maleico e os isocianatos. Há relatos de alguns estudos com isocianatos e silanos como agentes de acoplamento. Em geral, o uso desses agentes melhora significativamente as propriedades mecânicas dos compósitos [29].

$\mathrm{O}$ anidrido maleico possui cadeias longas de alta massa molecular que permitem a formação de emaranhamentos moleculares com a matriz polimérica na interface através de ancoramento mecânico [30-32].

Os isocianatos também são muito utilizados como agentes de acoplamento em diversos materiais devido a sua polaridade. Estes compostos possuem o grupo ativo NCO, que reage com a maioria dos materiais que contém hidrogênio. $\mathrm{O}$ isocianato faz ligação com a madeira sob condições de calor e umidade em temperatura ambiente [33], pois reage fortemente com os grupos hidroxila da madeira formando os carbamatos. $\mathrm{O}$ carbamato formado reage com o isocianato, de forma que quanto mais carbamato é formado, mais forte é a ligação do isocianato com a madeira. Entretanto, quando a madeira contém umidade, ocorre uma reação competitiva, pois o isocianato também reage com a água formando a poliuréia, dificultando a formação de carbamato, o que diminui a eficácia na ligação do isocianato com a madeira [34], o que reforça a importância da fase de secagem, anterior à exposição aos isocianatos. Dentre os isocianatos mais utilizados estão o difenilmetano diisocianato (MDI) e o tolueno diisocianato (TDI) [35].

Neste contexto, este trabalho visou estudar o reaproveitamento do resíduo de madeira rejeitado pelas indústrias moveleiras como reforço em matriz polimérica de PLLA, verificar a influência do MDI, bem como avaliar a influência do MDI juntamente com o aditivo Struktol® nas propriedades dos biocompósitos obtidos.

\section{MATERIAIS E MÉTODOS}

\subsection{Materiais}

O poli(L-ácido láctico) (PLLA) foi fornecido pela Natural Works, Estados Unidos da América, na forma de grânulos (massa molecular numérica média $\mathrm{M}_{\mathrm{n}}=105300 \mathrm{~g} / \mathrm{mol}$; massa molecular ponderal média $\mathrm{M}_{\mathrm{w}}=195$ $000 \mathrm{~g} / \mathrm{mol}$; Ip = 1,9). O resíduo de madeira Pinus (Pinus elliottii e Pinus taeda) foi fornecido pela empresa Grossl, situada em São Bento do Sul, Brasil. O RM foi peneirado em malhas de 1,40, 1,70 e 2,00 $\mathrm{mm}^{2}$. O MDI líquido foi doado pela Whirlpool, Brasil, a fim de avaliar a promoção da adesão interfacial entre o RM e o PLLA. O Struktol ${ }^{\circledR}$ TPW104 foi cedido pela Parabor (lote 4602PE). Trata-se de um lubrificante para processamento (injeção) indicado para compósitos de madeira plástica (PP e PE)

\subsection{Processamento dos biocompósitos}

Para produção dos pellets e obtenção das misturas foi realizada uma pré-homogeneização das matériasprimas com o objetivo de melhorar a incorporação, estas misturas foram processadas a $200 \mathrm{~min}^{-1} \mathrm{em} \mathrm{uma}$ extrusora dupla rosca co-rotante modelo MH-COR-20-32 LAB da MH Equipamentos com L/D 32, L = 640 $\mathrm{mm}$ e $\mathrm{D}=20 \mathrm{~mm}$. As condições de extrusão para todas as misturas estão ilustradas na Tabela 1. A zona 6 é a zona de degasagem, na qual foi realizado o vácuo. As misturas foram previamente secas em estufa com circulação de ar (Marconi MA 035) a $78^{\circ} \mathrm{C}$ por 24 h, devido à capacidade higroscópica desses materiais. Foram realizadas nas seguintes proporções 100/0, 80/20,70/30 e 60/40 \% (m/m) de misturas do polímero/RM, acondicionadas em embalagens plásticas do tipo zip, antes de serem peletizadas. 
Tabela 1: Condições de extrusão para todas as misturas.

\begin{tabular}{l|l|l}
\hline ZONA & $\begin{array}{l}\text { TEMPERATURA } \\
\text { PROGRAMADA }\left({ }^{\circ} \mathrm{C}\right)\end{array}$ & $\begin{array}{l}\text { TEMPERATURA } \\
\text { OBTIDA }\left({ }^{\circ} \mathrm{C}\right)\end{array}$ \\
\hline 1 & 120 & 107 \\
\hline 2 & 170 & 160 \\
\hline 3 & 175 & 172 \\
\hline 4 & 175 & 175 \\
\hline 5 & 180 & 181 \\
\hline 7 & 165 & 166 \\
\hline 8 & 170 & 170 \\
\hline 9 & 175 & 175 \\
\hline
\end{tabular}

O material extrudado foi então moído em moinho de facas para obtenção dos pellets, seguindo para injeção. O processo de transformação por injeção dos biocompósitos foi realizado em uma injetora HIMACO LHS 150/80. Os parâmetros utilizados e as temperaturas de injeção está sumarizado na Tabela 2 com base na literatura [36-41].

Para avaliar a influência da fração mássica de carga nas propriedades dos biocompósitos foram injetados corpos de prova contendo entre 0 e $40 \%(\mathrm{~m} / \mathrm{m})$ de resíduo de madeira (RM) (amostras PLLA/RM).

A fim de avaliar a promoção da adesão interfacial entre a carga vegetal e a matriz polimérica foram também processados por extrusão seguida por injeção corpos de prova com as mesmas frações mássicas de RM com a adição do MDI em 10 \% em massa, sem alterar os parâmetros de processamento (Tabelas 1 e 2) (amostras PLLA/RM/MDI).

Para avaliar a influência do uso de aditivo (Struktol $\left.{ }^{\circledR}\right)$ foram também processados corpos de prova com as mesmas frações mássicas de carga. Foram adicionados $2 \%$ em massa de Struktol® (amostras $\mathrm{PLLA} / \mathrm{RM} / \mathrm{MDI} / \mathrm{s})$.

Tabela 2: Parâmetros utilizados no processo de injeção dos biocompósitos.

\begin{tabular}{l|l}
\hline PARÂMETROS & DADOS PARA TODAS AS MISTURAS \\
\hline Pressão máxima de injeção & $1910 \mathrm{bar}$ \\
\hline Velocidade de preenchimento do molde & $94 \mathrm{~cm}^{3} / \mathrm{s}$ \\
\hline Temperatura do molde (frio) & $5{ }^{\circ} \mathrm{C}$ \\
\hline Bico (tempo acionado) & $30 \%$ por $30 \mathrm{~s}(9$ acionado e 21 desligado) \\
\hline Tempo de injeção (injeção + recalque) & $48 \mathrm{~s}$ \\
\hline Tempo de resfriamento & $12 \mathrm{~s}$ \\
\hline Pressão de injeção (bico) & $1910 \mathrm{bar}$ \\
\hline Fluxo de injeção (avanço de rosca) & $94 \mathrm{~cm}^{3} / \mathrm{s}$ \\
\hline Preção de recalque (bico) & $267,4 \mathrm{bar}$ \\
\hline
\end{tabular}


BITENCOURT, S.S.; BATISTA, K.C.; ZATTERA, A.J.; SILVA, D.A.K.; PEZZIN, A.P.T. revista Matéria, v.22, n.4, 2017.

\begin{tabular}{l|l}
\hline Fluxo de recalque (avanço de rosca) & $32,9 \mathrm{~cm}^{3} / \mathrm{s}$ \\
\hline Pressão de dosagem (bico) & $1910 \mathrm{bar}$ \\
\hline Fluxo de dosagem (retorno de rosca) & $94 \mathrm{~cm}^{3} / \mathrm{s}$ \\
\hline Velocidade de dosagem & $100 \mathrm{~min}^{-1}$ \\
\hline Temperatura de injeção Zona 1 & $190{ }^{\circ} \mathrm{C}$ \\
\hline Temperatura de injeção Zona 2 & $175^{\circ} \mathrm{C}$ \\
\hline Temperatura de injeção Zona 3 & $160{ }^{\circ} \mathrm{C}$ \\
\hline
\end{tabular}

\subsection{Caracterização dos biocompósitos}

Todos os corpos de prova para ensaios mecânicos obtidos nas proporções estabelecidas foram précondicionados de acordo com a norma ASTM D-618-13 [42], ou seja, a $23 \pm 2{ }^{\circ} \mathrm{C}$ e $50 \% \pm 5 \%$ de umidade relativa por no mínimo $48 \mathrm{~h}$ antes dos ensaios. Para todos os ensaios foram utilizados, no mínimo, 5 corpos de prova.

A elaboração dos corpos de prova para os ensaios de tração seguiu a norma ISO 527-1:2012 [43]. Os ensaios foram realizados em uma máquina Universal de ensaios da marca Emic DL10000 de acordo com a norma ASTM D-638-14 [44], com uma carga de $5000 \mathrm{~N}$, velocidade de $10 \mathrm{~mm} / \mathrm{min}$ e com o auxílio de extensômetro. Foram calculados os dados do módulo de elasticidade, resistência à tração e deformação na ruptura e apresentados como média e o respectivo desvio padrão.

Para análise termogravimétrica (TGA) as amostras foram previamente secas a $40{ }^{\circ} \mathrm{C}$ por $24 \mathrm{~h}$ e aquecidas de 25 a $600{ }^{\circ} \mathrm{C}$, com taxa de aquecimento de $10{ }^{\circ} \mathrm{C} / \mathrm{min}$ em atmosfera de nitrogênio no equipamento da TGA Q50 da TA Instruments.

As curvas de calorimetria exploratória diferencial (DSC) foram obtidas utilizando um equipamento DSC Q20 TA Instruments sob fluxo de nitrogênio. As amostras foram seladas em panelas de alumínio e aquecidas de 25 a $200{ }^{\circ} \mathrm{C}$ a uma taxa de aquecimento de $10{ }^{\circ} \mathrm{C} / \mathrm{min}$ (primeiro aquecimento) e mantidas a esta temperatura por $2 \mathrm{~min}$. Subsequentemente, elas foram resfriadas rapidamente até $-20^{\circ} \mathrm{C}$ (jumping) e aquecidas novamente até $200^{\circ} \mathrm{C}$ a uma taxa de aquecimento de $10^{\circ} \mathrm{C} / \mathrm{min}$ (segundo aquecimento).

A morfologia das amostras, bem como o grau de adesão foram avaliadas em um microscópio eletrônico de varredura DSM 940A Zeiss com $10 \mathrm{kV}$ de tensão de aceleração. As amostras foram recobertas com fina camada de ouro por deposição a vácuo utilizando um metalizador Baltec SCD 050.

Para os ensaios de absorção de água os corpos de prova dos biocompósitos (mínimo de 5) foram obtidos no formato quadrado com $25 \mathrm{~mm}$ de lado e com $2,8 \mathrm{~mm}$ de espessura, secos em estufa a vácuo por $50 \pm$ $3{ }^{\circ} \mathrm{C}$ por $8 \mathrm{~h}$, resfriados em um dessecador e foram obtidas imediatamente suas massas em balança analítica com resolução de $0,0001 \mathrm{~g}$. As amostras condicionadas foram imersas em água destilada, mantidas a $23 \pm 1$ ${ }^{\circ} \mathrm{C}$ até massa constante (saturação). A diferença entre a amostra saturada e a amostra seca foi considerada como a taxa de água absorvida pelo corpo de prova, segundo a norma ASTM D-570-98(2010) [45].

A densidade foi determinada por picnometria de gás hélio em um equipamento Micromeritics - Accu Pyr II V1.02. As medidas de volume foram realizadas com 10 expurgos (Equilib. Intervalo: 10 segundos; Volume de expansão: $8,1563 \mathrm{~cm}^{3}$; Volume celular: 2,9953 $\mathrm{cm}^{3}$ ).

O teor de vazios foi determinado seguindo a norma ASTM D-2734-16 [46]. A densidade teórica da amostra foi determinada de acordo com as equações 1 e 2 para os biocompósitos com MDI:

$$
\mathrm{T}=100(\mathrm{R} / \mathrm{D}+\mathrm{r} / \mathrm{d})
$$

onde: $\mathrm{T}=$ densidade teórica; $\mathrm{R}=\%$ em massa de PLLA no biocompósito; $\mathrm{D}=$ densidade de PLLA; $\mathrm{r}=\% \mathrm{em}$ massa de $\mathrm{RM}$ e $\mathrm{d}=$ densidade da $\mathrm{RM}$.

O teor de vazios foi calculado usando a equação (2):

$$
\mathrm{V}=100(\mathrm{~T}-\mathrm{Md}) / \mathrm{T}
$$


onde: $\mathrm{V}=$ teor de vazios, volume \%; $\mathrm{T}=$ densidade teórica e $\mathrm{Md}=$ densidade do biocompósitos determinada pelo ensaio.

Para o caso das amostras com Struktol® e MDI, este percentual foi levado em consideração para a determinação da densidade teórica.

Os espectros de FTIR foram obtidos usando um espectrofotômetro Perkin-Elmer Spectrum One B, em 12 varreduras na região espectral de 4000 a $650 \mathrm{~cm}^{-1}$, com resolução de $4 \mathrm{~cm}^{-1}$, utilizando o acessório de reflectância total atenuada (ATR).

Para avaliar a biodegradação dos biocompósitos, o solo foi preparado misturando partes iguais de solo fértil, esterco de cavalo e areia de praia (4 mesh) e deixado envelhecer de 3 meses monitorando-se o $\mathrm{pH}$ (6.5 a 7.5) e a umidade (20 a 30\%) de acordo com a norma ASTM G160 - 98 [47]. A terra foi acondicionada em copos de Becker de $1 \mathrm{~L}$ com cerca de $15 \mathrm{~cm}$ de altura, sendo estes mantidos a $30 \pm 2{ }^{\circ} \mathrm{C}$ e umidade de 85 a 95 $\%$. As amostras foram enterradas em 2 copos de Becker (duplicatas), contendo 1 amostra cada (duplicata). Após 5 meses, as amostras foram removidas do solo, cuidadosamente lavadas em água e secas em estufa a vácuo a $20{ }^{\circ} \mathrm{C}$ por $24 \mathrm{~h}$. Foram utilizadas 2 amostras para cada composição para cada tempo (duplicata). As amostras PLLA/RM/MDI/s, nas proporções 100, 80/20, 70/30 e 60/40 foram enterradas por 5 meses, sendo que a degradação foi acompanhada por análise visual, TGA e DSC.

\section{RESULTADOS E DISCUSSÃO}

\subsection{Processamento dos biocompósitos}

A extrusão e a injeção dos biocompósitos foram realizadas em parceria com a Universidade de Caxias do Sul (UCS), no Laboratório de Materiais. Na Figura 1 estão ilustradas as principais etapas do processo de extrusão.
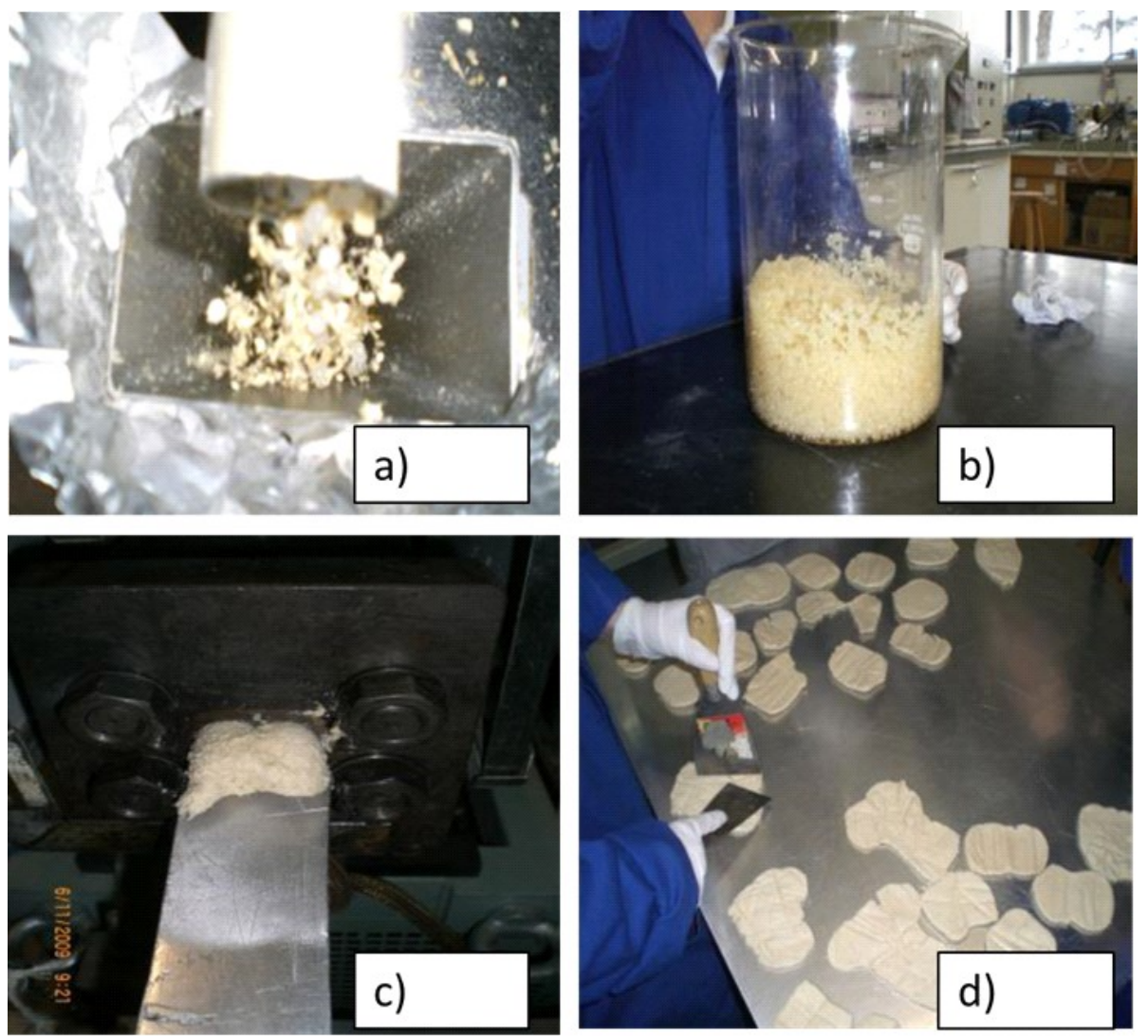

Figura 1: Etapas do processo de extrusão: a) mistura do MDI com PLLA; b) alimentação da extrusora; c) material extrudado; d) resfriamento do material. 
Foi visível a interferência da fase dispersa no processo de extrusão, sendo que quanto maior o percentual de RM, mais difícil tornava-se o processamento e se observava uma diferença na aparência do material, ou seja, mais compactado (pastoso) e escuro tornava-se o material. O aumento da concentração de RM, também dificultou o processo de injeção dos biocompósitos. A aparência dos biocompósitos após o processo de injeção pode ser observada na Figura 2. Observa-se o escurecimento das amostras com o aumento de RM, com a adição do MDI e com adição de Struktol ${ }^{\circledR}$.

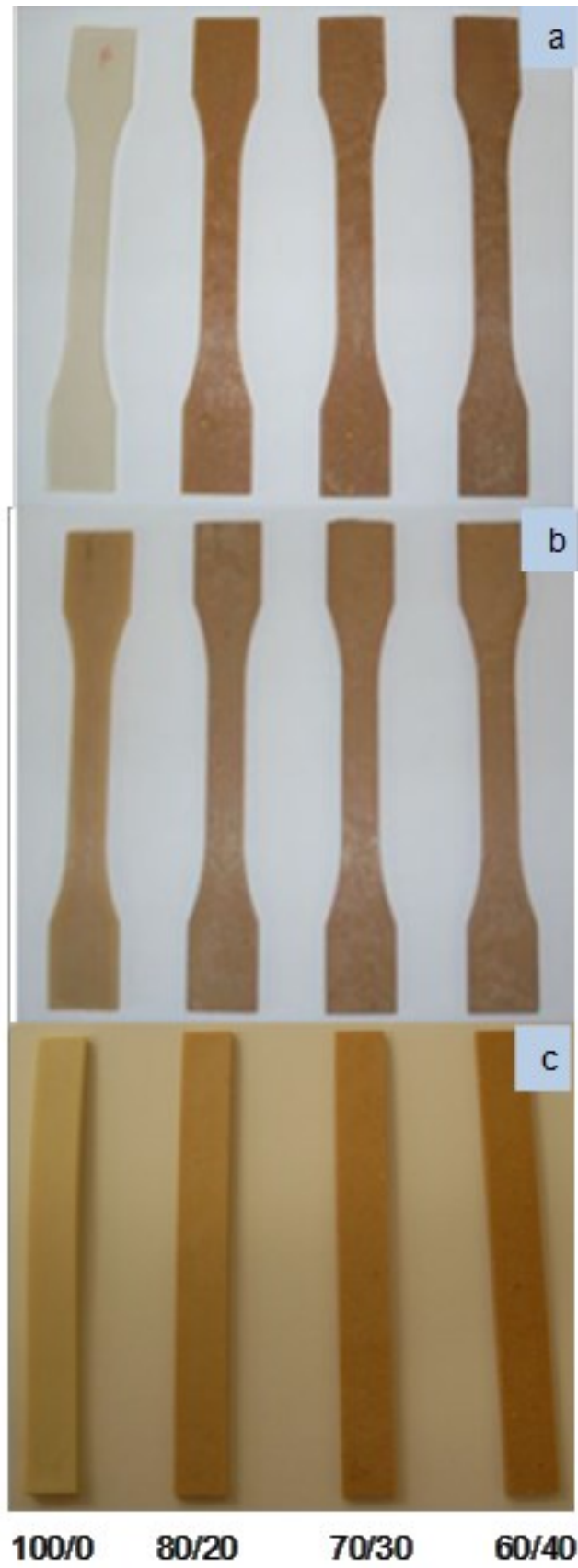

Figura 2: Fotografia dos biocompósitos injetados: a) PLLA/RM; b) PLLA/RM/MDI; c) PLLA/RM/MDI/s. 


\subsection{Caracterização dos biocompósitos}

\subsubsection{Ensaio de tração}

Na Figura 3 estão apresentados os resultados do ensaio mecânico sob tração, módulo de Young e alongamento na ruptura para todos os biocompósitos estudados. A resistência à tração obtida para o PLLA puro foi de $59,41 \pm 2,79 \mathrm{MPa}$, dentro do esperado para este polímero.

Os valores de resistência à tração (Figura 3a) para o PLLA puro encontrados na literatura foram de 55 MPa [48] e $63 \mathrm{MPa}$ [41]. Em relação aos biocompósitos, houve um decréscimo de cerca de $16 \%$ com a adição de 20 (\% massa) de RM. Independentemente do percentual de resíduo incorporado à amostra esta propriedade sofreu o mesmo decréscimo. Comparando os biocompósitos com a mesma proporção de RM, a presença de MDI incrementou a resistência à tração de forma significativamente para todas as composições avaliadas. A resistência à tração do biocompósito com 40 (\% massa) de RM foi $30 \%$ superior e $66 \%$ inferior com a adição de Struktol ${ }^{\circledR}$, indicando a ação do MDI como agente de acoplamento. Ocorreu um aumento significativo da rigidez do material de 73 \% para os biocompósitos com adição de $40(\% \mathrm{~m} / \mathrm{m})$ de RM. Wang et al. (2001) [49] estudaram blendas de PLA/amido de trigo na proporção de $55 / 45(\% \mathrm{~m} / \mathrm{m})$ sem e com adição de MDI. A resistência à tração também foi superior para as blendas com MDI, confirmando a ação do agente de acoplamento. Os ensaios de tração dos biocompósitos mostraram pouca alteração no alongamento com o aumento da proporção de serragem. Entretanto, o MDI melhorou de forma significativa o alongamento na ruptura se comparado ao mesmo material sem o uso de MDI, como observado na Figura 3c.

O módulo de Young ou módulo de elasticidade é um parâmetro mecânico que proporciona uma medida da rigidez de um material sólido. Obtém-se da razão entre a tensão exercida e a deformação unitária sofrida pelo material. Quanto maior esse módulo, maior a tensão necessária para o mesmo grau de deformação, e, portanto, mais rígido é o material. A relação linear entre essas grandezas é conhecida como lei de Hooke [50].

Na Figura $3 b$ estão mostrados os resultados obtidos para o módulo de Young dos biocompósitos. A análise da influência do resíduo de madeira nos biocompósitos sem adição de MDI mostrou que o aumento na concentração de RM, aumentou significativamente a rigidez dos biocompósitos. O módulo de Young determinado para o PLLA puro, foi de $3,45 \pm 0,44 \mathrm{GPa}$ enquanto que para o biocompósito $60 / 40$ ( $\%$ PLLA/RM) foi de 5,98 $\pm 0,45 \mathrm{GPa}$, representando um incremento significativo aproximado de $73 \%$, tornando assim o material mais rígido. Huda et al. (2005) [38] estudaram biocompósitos de PLA e fibra de madeira e observaram que o módulo de Young aumentou significativamente com a adição de fibra de madeira de 2,7 $\pm 0,4 \mathrm{GPa}$ para o PLA puro e $6,3 \pm 0,9 \mathrm{GPa}$ com 40 (\% massa) de resíduo de madeira, mas a resistência à tração também decresceu como aumento da fração de fibra de madeira, provavelmente em função da baixa agregação entre o polímero e a fibra, o que justifica a necessidade de um agente de acoplamento. Na presença de MDI foi obtido valor de 3,30 \pm 0,51 GPa para o PLLA/MDI e 5,03 \pm 0,68 GPa para o biocompósito com $40(\% \mathrm{~m})$ de RM. Com esta informação verifica-se que o MDI e de MDI + Struktol® não exerceram influência significativa nos valores de módulo de Young, como se observa pelo desvio padrão com até $30 \%$ de adição de serragem.

O alongamento na ruptura (Figura 3c) para os biocompósitos diminuiu significativamente com o aumento do teor de serragem, passando de 2,29 $\pm 0,48 \%$ do PLLA puro para 0,82 $\pm 0,07 \%$, com 40\% $(\mathrm{m} / \mathrm{m})$, representando um decréscimo de $36 \%$. Por outro lado, é visível que a presença do MDI melhorou de forma significativa esta propriedade quando comparado aos biocompósitos com apenas serragem. Ocorreu um incremento desta propriedade com a adição do MDI quando comparado aos biocompósitos com apenas RM. Já com a adição do Struktol ${ }^{\circledR}$ houve uma diminuição do alongamento na ruptura, comparado tanto com resíduo de madeira quanto com adição do MDI. 

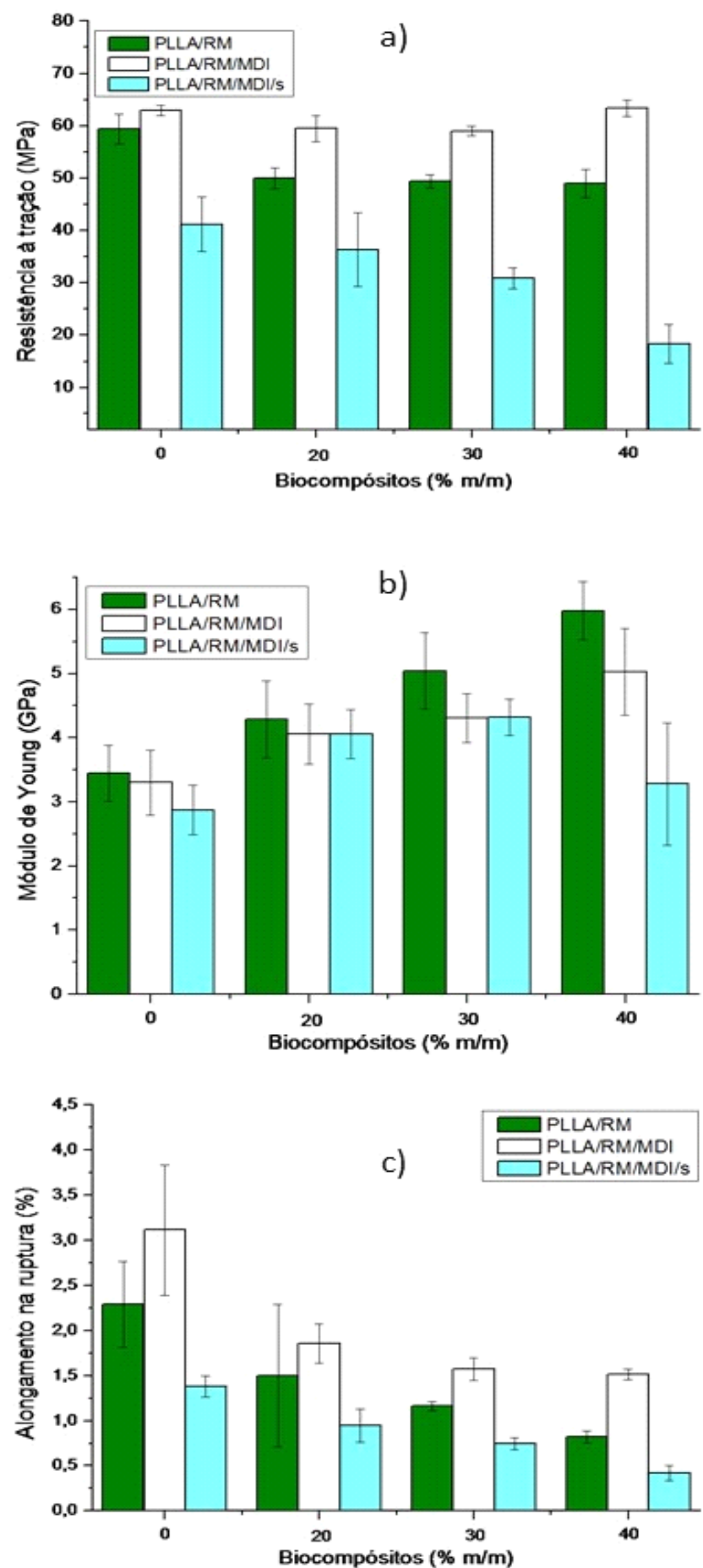

Figura 3: Dados obtidos pelo ensaio de tração para os biocompósitos de PLLA/RM: a) resistência à tração; b) módulo de Young; c) alongamento na ruptura. 


\subsubsection{Calorimetria exploratória diferencial (DSC)}

Na Figura 4 estão apresentadas as curvas de DSC dos biocompósitos e os dados obtidos das curvas de DSC estão relacionados na Tabela 3. O PLLA apresentou temperatura de transição vítrea $\left(\mathrm{T}_{\mathrm{g}}\right)$ em $59{ }^{\circ} \mathrm{C}$, característica desse polímero, devido à sua elevada rigidez. A temperatura de fusão cristalina do PLLA foi em 149 ${ }^{\circ} \mathrm{C}$, entalpia de fusão $\left(\Delta \mathrm{H}_{\mathrm{m}}\right)$ de $7,3 \mathrm{~J} / \mathrm{g}$ e grau de cristalinidade $\left(\alpha_{\mathrm{c}}\right)$ de 7,8\%. O “ombro" exotérmico que ocorre antes do pico de fusão é uma cristalização pré-fusão, também característica desse polímero. Observase que a $T_{g}$ e a $T_{m}$ do PLLA não sofre nenhuma variação com a adição de $R M$, independentemente da quantidade de resíduo adicionada. Já o $\Delta \mathrm{H}_{\mathrm{m}}$ diminui para 1,5 e 2,0 J/g com a adição de 20 e $30 \%$ de RM, respectivamente, indicando que a adição de até $30 \%$ de RM abaixou a cristalinidade do PLLA passando de 1,3 para $1,5 \%$, voltando a subir para 7,9\% com $40 \%$ de RM.

A presença de MDI na amostra de PLLA diminui a $\mathrm{T}_{\mathrm{g}}$ do PLLA de 59 para $54{ }^{\circ} \mathrm{C}$, indicando pequeno aumento da flexibilidade do material, mas com a presença de madeira, a $T_{g}$ sobe para valores entre 59 e 60 ${ }^{\circ} \mathrm{C}$, mostrando um aumento de rigidez dos biocompósitos. A $\mathrm{T}_{\mathrm{m}}$ das amostras com MDI permaneceu praticamente constante, variando de 146 a $149^{\circ} \mathrm{C}$. O aumento do $\Delta \mathrm{H}_{\mathrm{m}}$ do PLLA com a adição de MDI, indica um aumento do $\alpha \mathrm{c}$ do PLLA passando de 7,8 para $15,7 \%$. Nas amostras com MDI, o $\Delta \mathrm{H}_{\mathrm{m}}$ não varia de forma gradual, ou seja, a adição de $20 \%$ de RM diminui para 5,2 \% a cristalinidade do polímero, com $30 \%$ de RM a cristalinidade é aumentada para $18,9 \%$ e com $40 \%$ de RM esse valor volta a cair para $6,3 \%$.

As amostras com adição de Struktol ${ }^{\circledR}$ também não apresentaram alteração na $T_{g}$, mas observa-se em todas elas o aparecimento de um segundo pico de fusão em temperatura mais baixa, característico de cristais menores. Esse comportamento pode indicar degradação decorrente da cisão das cadeias poliméricas. Observa-se também que a adição de Struktol ${ }^{\circledR}$ aumenta significativamente o $\Delta \mathrm{H}_{\mathrm{m}}$, se comparado com PLLA/RM, nas diferentes proporções, indicando um aumento no $\alpha_{c}$ do PLLA. 

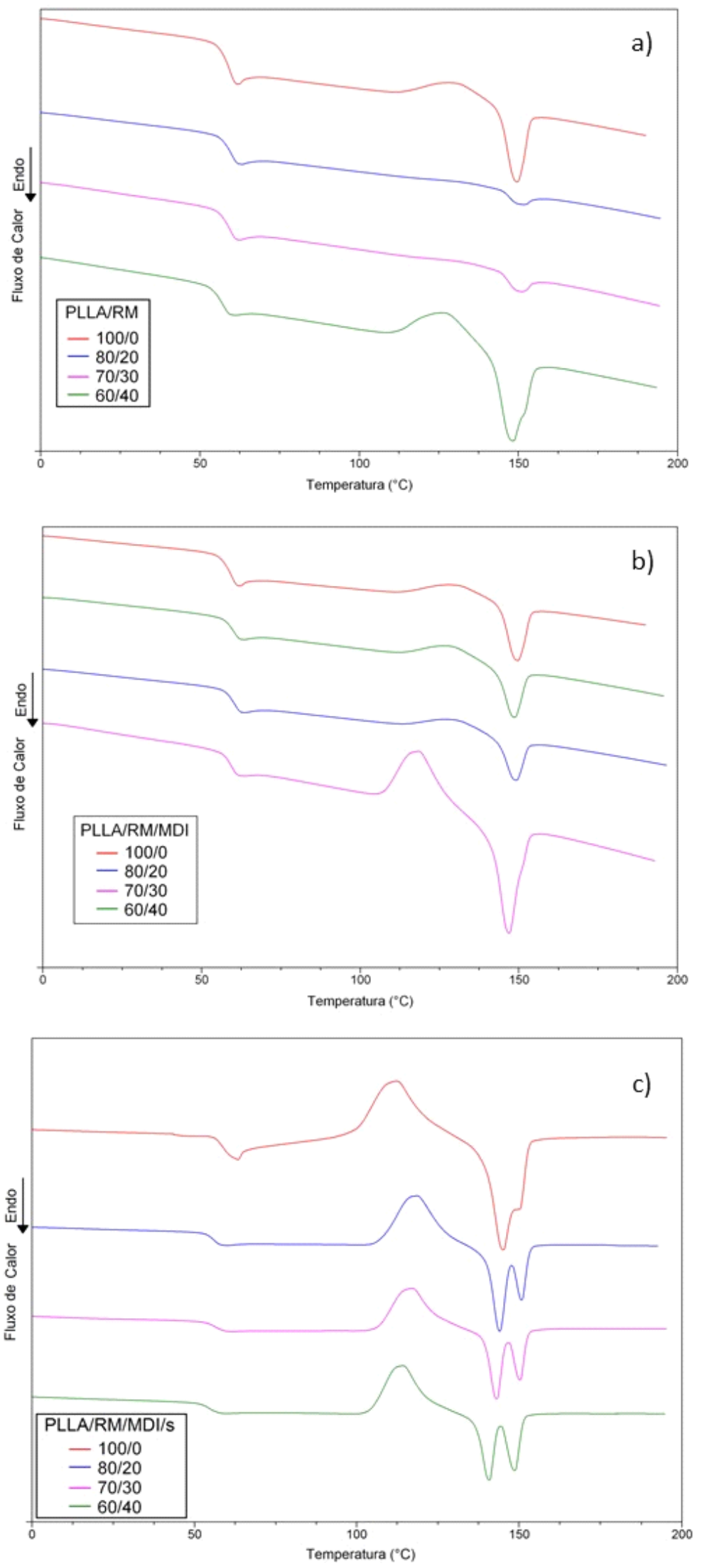

Figura 4: Curvas de DSC dos biocompósitos: a) PLLA/RM; b) PLLA/RM/MDI; c) PLLA/RM/MDI/s. 
Tabela 3: Dados obtidos a partir das curvas de DSC dos biocompósitos.

\begin{tabular}{|c|c|c|c|c|}
\hline AMOSTRAS & $\mathrm{T}_{\mathrm{g}}\left({ }^{\circ} \mathrm{C}\right)$ & $\mathrm{T}_{\mathrm{m}}\left({ }^{\circ} \mathrm{C}\right)$ & $\Delta H_{m}(J / G)$ & $\alpha_{c}(\%)$ \\
\hline PLLA/RM 100/0 & 59 & 149 & 7,3 & 7,8 \\
\hline PLLA/RM 80/20 & 60 & 150 & 1,5 & 1,3 \\
\hline PLLA/RM 70/30 & 59 & 150 & 2,0 & 1,5 \\
\hline PLLA/RM 60/40 & 57 & 148 & 12,4 & 7,9 \\
\hline PLLA/RM/MDI 100/0 & 54 & 146 & 16,4 & 15,7 \\
\hline PLLA/RM/MDI 80/20 & 60 & 149 & 5,4 & 5,2 \\
\hline PLLA/RM/MDI 70/30 & 60 & 147 & 19,7 & 18,9 \\
\hline PLLA/RM/MDI 60/40 & 60 & 148 & 6,6 & 6,3 \\
\hline PLLA/RM/MDI/s 100/0 & 59 & 145 & 31,3 & 29,4 \\
\hline PLLA/RM/MDI/s 80/20 & 56 & 144 & 20,6 & 19,3 \\
\hline $\mathrm{PLLA} / \mathrm{RM} / \mathrm{MDI} / \mathrm{s}$ 70/30 & 56 & 143 & 16,3 & 15,3 \\
\hline PLLA/RM/MDI/s 60/40 & 54 & 141 & 18,1 & 17,0 \\
\hline
\end{tabular}

$\mathrm{T}_{\mathrm{g}}=$ temperatura de transição vítrea; $\mathrm{T}_{\mathrm{m}}=$ temperatura de fusão cristalina; $\Delta \mathrm{H}_{\mathrm{m}}=$ entalpia de fusão; $\alpha_{\mathrm{c}}=$ grau de cristalinidade. Para os cálculos de $\alpha_{c}$ foi levado em consideração o percentual de PLLA nas amostras.

\subsubsection{Análise termogravimétrica (TGA)}

Na Figura 5 estão apresentadas as curvas TG dos biocompósitos obtidas por TGA e a Tabela 4 relaciona os dados obtidos das curvas TG e DTG. O PLLA apresenta somente um estágio de perda de massa, com temperatura de degradação $\left(\mathrm{T}_{\text {onset }}\right)$ em $345^{\circ} \mathrm{C}$. Entretanto, nota-se que a $\mathrm{T}_{\text {onset }}$ do PLLA é superior quando comparada com outros trabalhos $\left(\mathrm{T}_{\text {onset }}=306^{\circ} \mathrm{C}\right)$. De uma forma geral, a adição de $\mathrm{RM}$ diminuiu a estabilidade térmica dos biocompósitos, sendo que com a incorporação de $40(\% \mathrm{~m})$ de resíduo este decréscimo foi de 27 ${ }^{\circ} \mathrm{C}$. Silva et al. (2014) [51] também constataram um decréscimo de $8{ }^{\circ} \mathrm{C}$ com a incorporação de $40 \%$ de RM em matriz de PHBV. A presença de MDI nas amostras exerceu pouca influência na estabilidade térmica dos biocompósitos, sendo que com $40(\% \mathrm{~m})$ a $\mathrm{T}_{\text {onset }}$ foi exatamente a mesma $\left(\mathrm{T}_{\text {onset }}=318^{\circ} \mathrm{C}\right)$ quando comparado com PLLA/RM 60/40. Por outro lado, a presença de Struktol® nas amostras exerceu bastante influência diminuindo de forma significativa a estabilidade térmica tanto do polímero puro, quanto dos biocompósitos, passando de $\mathrm{T}_{\text {onset }}=345^{\circ} \mathrm{C}$ para $\mathrm{T}_{\text {onset }}=267{ }^{\circ} \mathrm{C}$. Nos biocompósitos com adição de $40 \%$ de RM houve um decréscimo de $51^{\circ} \mathrm{C}$. Em relação à perda de massa, a presença do MDI e Struktol ${ }^{\circledR}$ interferiram no percentual da perda de massa elevando a quantidade de resíduo ao final da análise. 

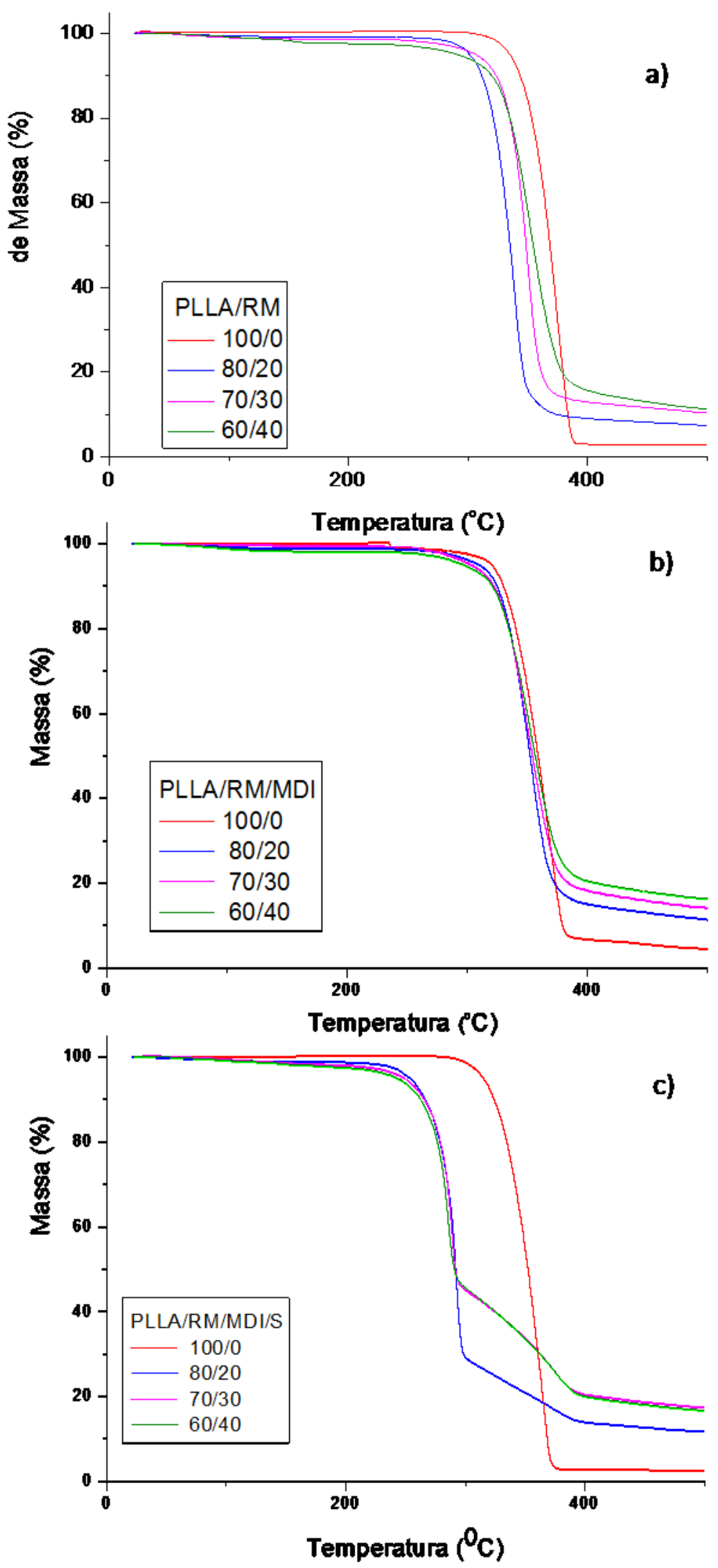

Figura 5: Curvas TG obtidas por TGA para os biocompósitos: (a) PLLA/RM, (b) PLLA/RM/MDI (c) PLLA/RM/MDI/s. 
Tabela 4: Dados obtidos por TGA para os biocompósitos PLLA/RM, PLLA/RM/MDI e PLLA/RM/MDI/s.

\begin{tabular}{|c|c|c|c|}
\hline AMOSTRAS & $\mathrm{T}_{\text {onset }}\left({ }^{\circ} \mathrm{C}\right)$ & $\mathrm{T}_{\text {máx }}\left({ }^{\circ} \mathrm{C}\right)$ & PERDA DE MASSA (\%) \\
\hline PLLA/RM 100/0 & 345 & 374 & 96,51 \\
\hline PLLA/RM 80/20 & 312 & 339 & 97,65 \\
\hline PLLA/RM 70/30 & 331 & 350 & 99,72 \\
\hline PLLA/RM 60/40 & 318 & 374 & 91,55 \\
\hline PLLA/RM/MDI 100/0 & 333 & 368 & 96,02 \\
\hline PLLA/RM/MDI 80/20 & 323 & 353 & 90,91 \\
\hline PLLA/RM/MDI 70/30 & 321 & 351 & 87,64 \\
\hline PLLA/RM/MDI 60/40 & 318 & 355 & 88,56 \\
\hline PLLA/RM/MDI/s 100/0 & 267 & 295 & 98,83 \\
\hline PLLA/RM/MDI/s 80/20 & 270 & 292 & 90,12 \\
\hline PLLA/RM/MDI/s 70/30 & 269 & 289 & 84,68 \\
\hline PLLA/RM/MDI/s 60/40 & 267 & 285 & 85,60 \\
\hline
\end{tabular}

$\mathrm{T}_{\text {onset }}=$ temperatura de degradação e $\mathrm{T}_{\text {máx }}=$ temperatura onde a degradação é máxima.

\subsubsection{Microscopia eletrônica de varredura (MEV)}

Na Figura 6 estão mostradas as fotos dos biocompósitos. Observa-se um padrão típico de fratura frágil, característico do PLLA, que é um polímero rígido e quebradiço. Para os biocompósitos, nota-se uma boa dispersão do resíduo na matriz, sendo difícil identificar a presença do resíduo nas amostras com percentuais de RM inferiores a $40 \%$. Huda et al. (2006) [52] também conseguiram uma boa dispersão de entre as fibras de jornal reciclado e a matriz de PLA. Para os compósitos com um percentual de RM acima de $30 \%$ foi possível observar lacunas que sugerem a remoção das partículas de RM (círculo vermelho). No entanto, as cavidades observadas nas amostras com MDI são menores do que aquelas observadas nas amostras com apenas 30 ou $40 \% \mathrm{RM}$, confirmando assim os resultados registrados para módulo de Young e alongamento na ruptura, indicando que as amostras se tornaram mais flexíveis. O acréscimo do Struktol@ não interferiu na morfologia das fraturas em relação aos biocompósitos com MDI. 


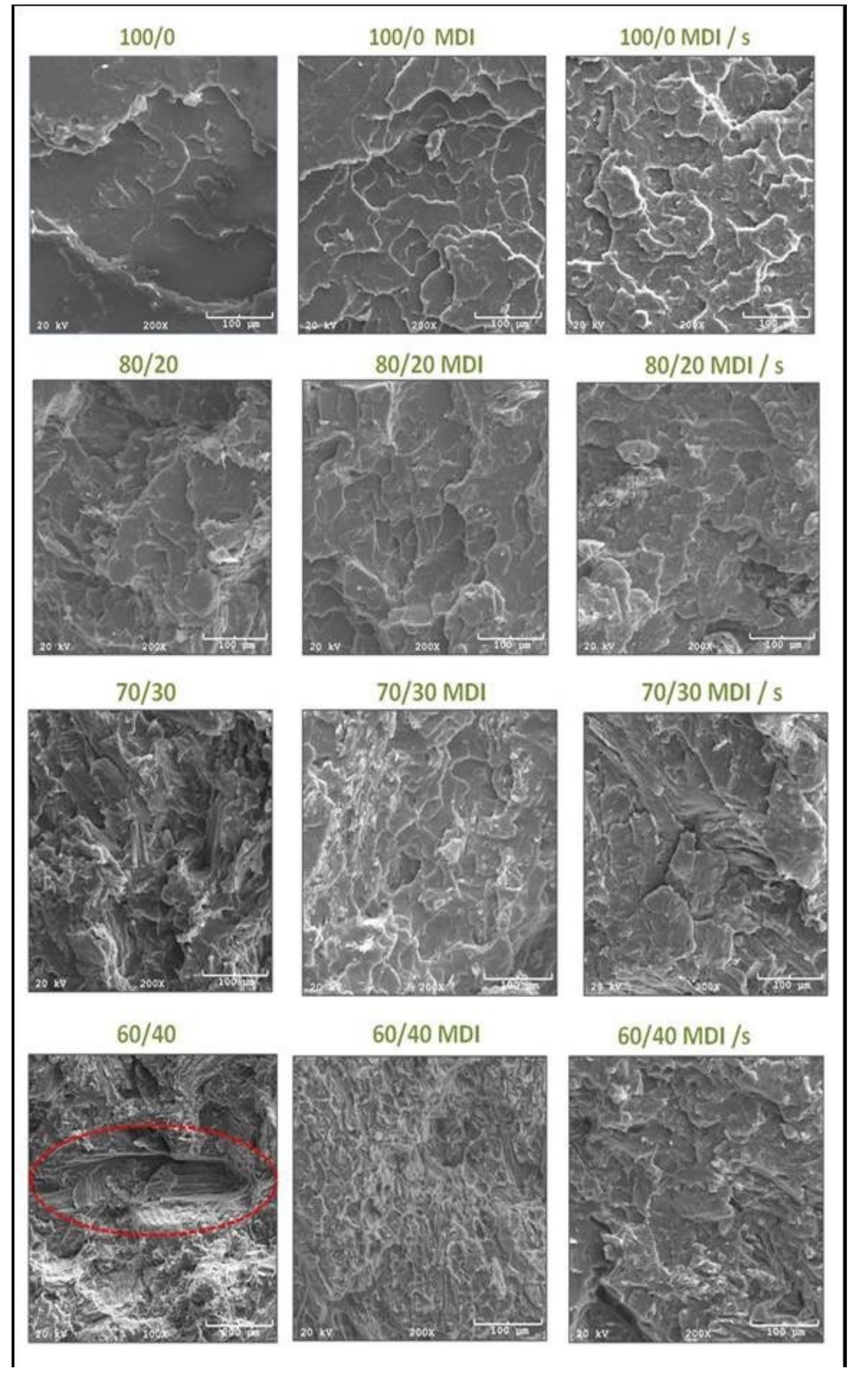

Figura 6: Micrografias obtidas por MEV das superfícies de fraturas de tração dos biocompósitos (200X): (a)100/0, (b) 100/0/MDI, (c) 100/0/MDI/s, (d) 80/20, (e) 80/20/MDI, (f) 80/20/MDI/s, (g) 70/30, (h) 70/30/MDI, (i) 70/30/MDI/s, (j) 60/40, (k) 60/40/MDI, (l) 60/40/MDI/s. 


\subsubsection{Absorção de água}

Na Figura 7 estão apresentadas as taxas de absorção de água dos biocompósitos, que seguem um comportamento Fickiano, apresentando uma parte linear inicial seguida de um platô de equilíbrio. Na Figura 7a, constata-se que o PLLA chegou à saturação bem antes dos biocompósitos. A absorção de água do PLLA puro mostrou-se inferior à absorção dos biocompósitos, estabilizando em cerca de $0,76 \pm 0,008 \%$ após 840 h. $O$ RM exerceu grande influência sobre a absorção dos biocompósitos, acarretando no incremento da taxa de absorção de água com o aumento do teor de RM incorporado às amostras, devido à alta hidrofilicidade deste resíduo. Os biocompósitos com MDI (Figura 7b) apresentaram diminuição da absorção de água quando comparados àqueles sem o agente de acoplamento. A amostra com $40 \%$ de RM absorveu 9,75 $\pm 0,62 \%$ de água, enquanto a mesma amostra com MDI absorveu 6,64 $\pm 0,26 \%$ de água, uma diminuição de 32,0 \%. Tal fato pode ser explicado em função do MDI promover maior adesão do PLLA com o RM, acarretando na diminuição dos vazios, como observado por MEV os vazios proporcionam a entrada de água nas interfaces do PLLA/RM. As amostras com Struktol ${ }^{\circledR}$ (Figura 7c) não apresentaram absorção de água, nas primeiras 168 h. Depois deste período a taxa de absorção de água, no equilíbrio, foi superior as amostras sem MDI. No caso da composição $40 \%$ de RM esta absorveu 10,5 \pm 0,80 de água e sem MDI de 9,75 $\pm 0,62 \%$, significando um aumento de 7 \%. De maneira geral, sem a interferência do MDI ou do Struktol ${ }^{\circ}$, a medida que se aumenta a concentração de RM nos biocompósitos, existe o incremento da absorção de água, uma vez que se aumenta a quantidade de interfaces matriz/fibra visto nas micrografias dos biocompósitos (Figura 6), o que interfere também diretamente nas propriedades mecânicas do material. 

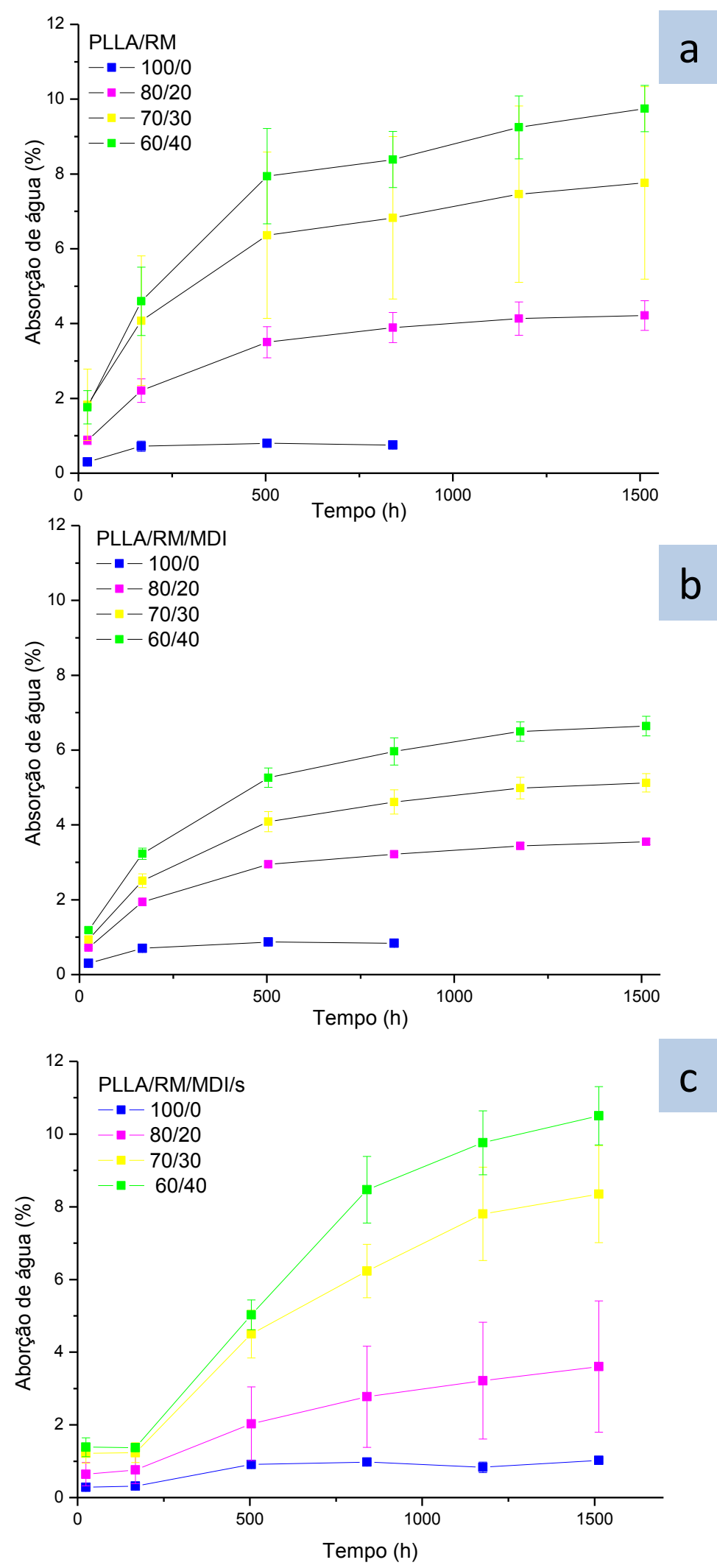

C

Figura 7: Resultados de absorção de água para os biocompósitos: a) PLLA/RM; b) PLLA/RM/MDI; c) $\mathrm{PLLA} / \mathrm{RM} / \mathrm{MDI} / \mathrm{s}$. 


\subsubsection{Densidade e teor de vazios}

Na Figura 8a podem ser visualizadas as densidades do biocompósitos. Observa-se uma tendência de aumento da densidade com a incorporação do RM. Tal fato era esperado uma vez que a densidade do RM $\left(1,72 \mathrm{~g} / \mathrm{cm}^{3}\right)$ é maior que a do PLLA $\left(1,25 \mathrm{~g} / \mathrm{cm}^{3}\right)$. Os biocompósitos com $40 \%$ de RM apresentaram um incremento na densidade de $7 \%$ quando comparados ao PLLA puro. Tanto o MDI quanto o Struktol ${ }^{\circledR}$, não exerceram influência significativa na densidade das amostras, exceto para o biocompósito com $20 \%$ de RM. Na Figura $8 \mathrm{~b}$ observa-se que o teor de vazios para os biocompósitos com quantidade mais elevada de RM foi significativamente inferior na presença de MDI, representando um decréscimo de $44 \%$ na amostra com $30(\% \mathrm{~m})$, concordando com os resultados observados por MEV. Entretanto, o MDI ocasionou um comportamento inverso no teor de vazios da amostra com $20(\% \mathrm{~m})$ de RM, sugerindo que a quantidade de RM não era suficiente para promover a ação do MDI. O acréscimo de Struktol ${ }^{\circledR}$ aumentou drasticamente o percentual de teor de vazios independente do percentual de RM dos biocompósitos, o que pode justificar o desempenho dessas amostras nos resultados de resistência à tração e alongamento na ruptura.
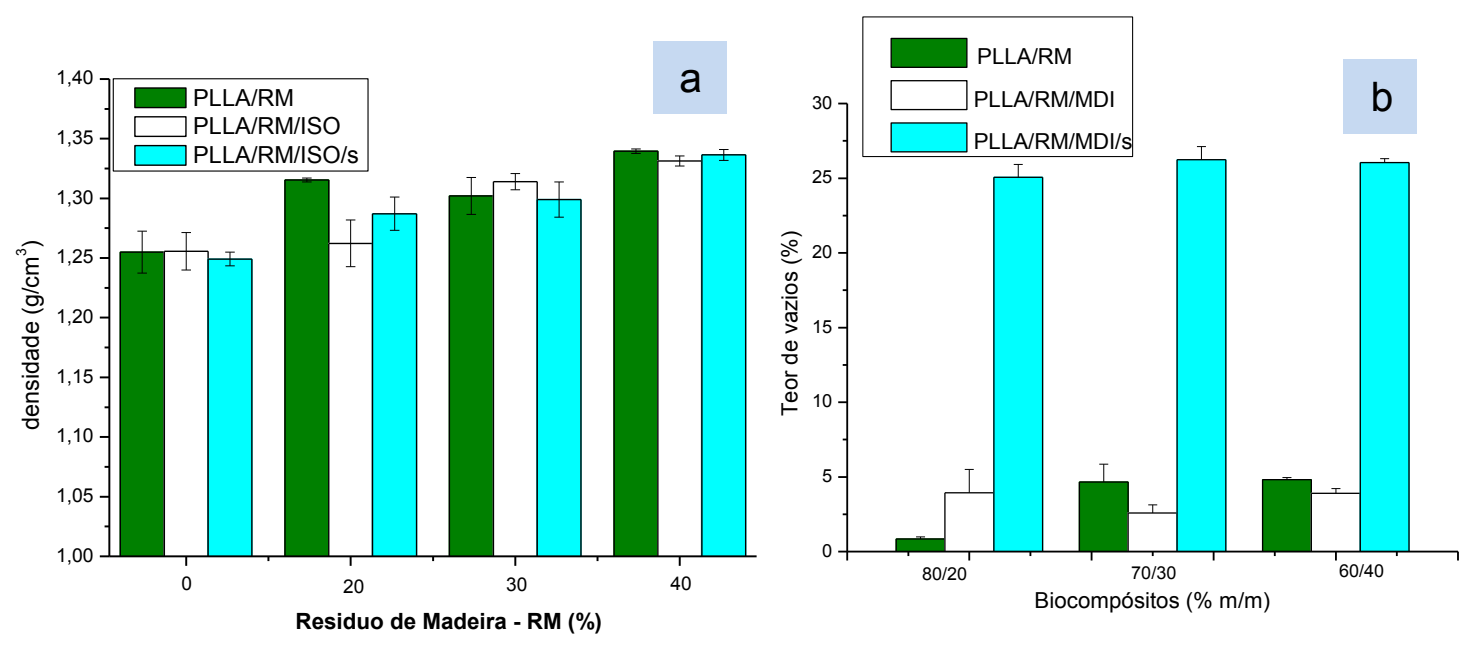

Figura 8: a) densidade e b) teor de vazios para os biocompósitos de PLLA/RM, PLLA/RM/MDI e PLLA/RM/MDI/s.

\subsubsection{Espectroscopia no infravermelho com transformada de Fourier (FTIR)}

Os espectros de FTIR do PLLA/RM, PLLA/RM/MDI e PLLA/RM/MDI/s estão demostrados na Figura 9. Na Figura 9a, são visíveis as bandas características do PLLA, um pico intenso em $1748 \mathrm{~cm}^{-1}$ atribuído ao estiramento de $\mathrm{C}=\mathrm{O}(\mathrm{J} \mathrm{C}=\mathrm{O}$ do $\mathrm{COO})$, uma banda em $1181 \mathrm{~cm}^{-1}$ relativa ao estiramento simétrico do $\mathrm{J}_{\mathrm{s}} \mathrm{C}-\mathrm{O}-\mathrm{C}$ e outra banda em $1082 \mathrm{~cm}^{-1}\left(J\right.$ as C-O-C do COC). Observa-se também bandas em $2995 \mathrm{~cm}^{-1}, 1359 \mathrm{~cm}^{-1}, 1454$ $\mathrm{cm}^{-1}$ ( $\delta$ as C-H do $\mathrm{CH}_{3}$ ), 1129 e $1043 \mathrm{~cm}^{-1}$ (J C-C), 870 e $754 \mathrm{~cm}^{-1}$ atribuídos ao estiramento do C-H. A presença de umidade pode ser visualizada no espectro pelo aparecimento de uma banda em $3550 \mathrm{~cm}^{-1}$ (J OH) [53]. Estas atribuições estão de acordo com a literatura [54], sendo que a alteração mais efetiva foi a redução da intensidade da banda em $1748 \mathrm{~cm}^{-1}$, não sendo caracterizado o efeito do resíduo nas composições. Quanto ao efeito do MDI nas amostras, os espectros apresentados na Figura $9 \mathrm{~b}$ não se observa a banda relativa ao grupo $\mathrm{O}=\mathrm{C}=\mathrm{N}$ em nenhum dos espectros, sugerindo que houve reação do MDI nessas amostras. Com a adição de Struktol ${ }^{\circledR}$ (Figura 9c), foi possível localizar bandas relacionadas ao estiramento do grupo $\mathrm{CH}_{2}(\mathrm{~J} s)$ em $2820-2760 \mathrm{~cm}^{-1}$ e de deformação angular simétrica ( $\left.{ }^{\mathrm{T} M} \mathrm{~s}\right)$ desse grupo entre 1450 e $1405 \mathrm{~cm}^{-1}$, além da banda de amida secundária em $1571-1525 \mathrm{~cm}^{-1}$. A presença dessas bandas condiz com a composição prevista para o Struktol®, ou seja, ácido carboxílico, estearato de zinco, mono e diamidas. 

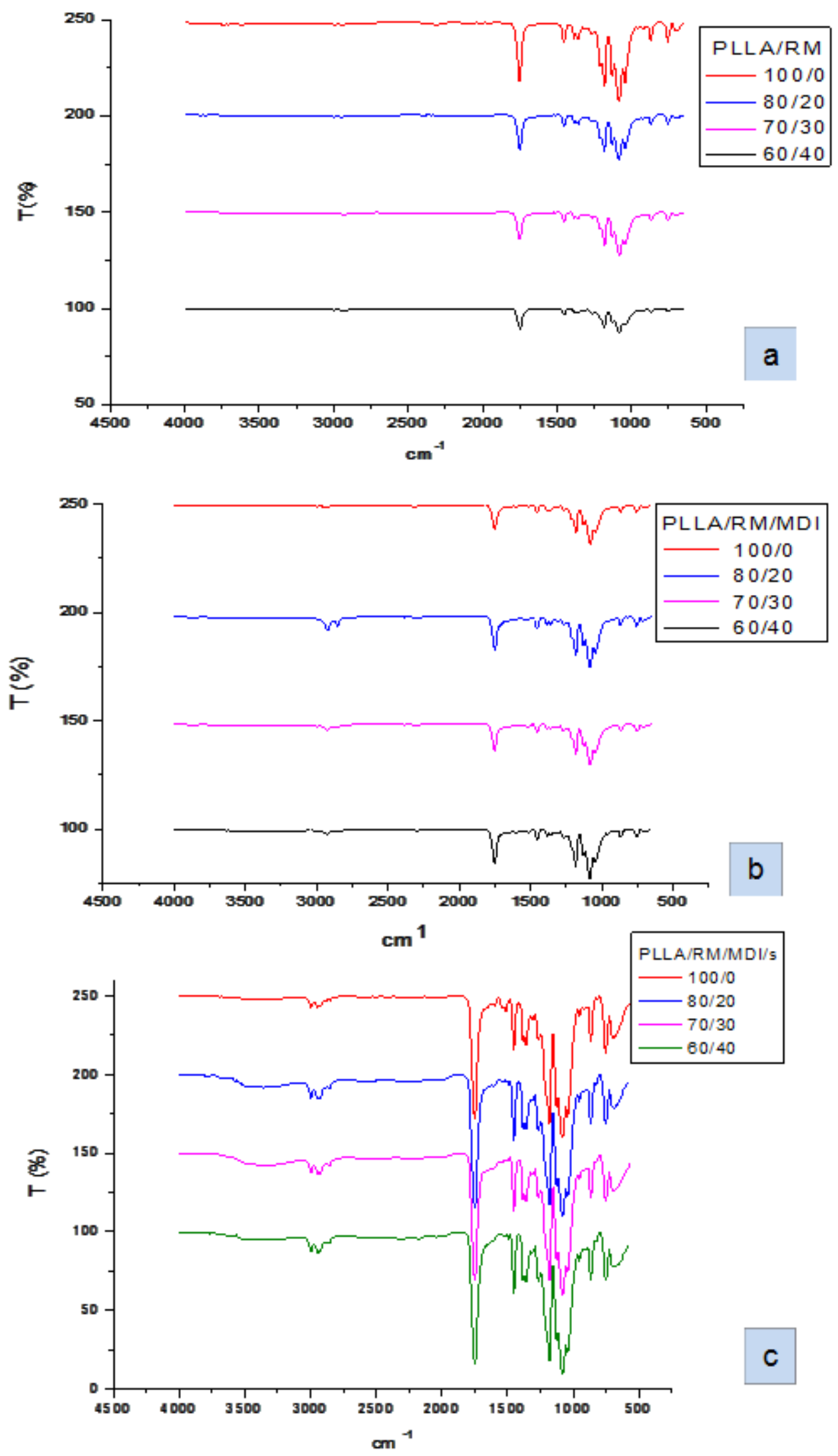

Figura 9: Espetros de FTIR dos biocompósitos: a) PLLA/RM; b) PLLA/RM/MDI; c) PLLA/RM/MDI/s. 


\subsection{Biodegradação em solo dos biocompósitos}

\subsubsection{Análise visual}

A fotografia dos biocompósitos de PLLA/RM/MDI/s antes e após 5 meses de biodegradação em solo é observada na Figura 10 e revela que não houve alteração visual na amostra 100/0, enquanto a composição 80/20 apresentou um leve escurecimento após o ensaio. As amostras 70/30 e 60/40 mostraram-se bem mais escuras em relação às sem biodegradação, com a presença de pequenos pontos escuros distribuídos homogeneamente por toda a amostra. Assim, torna-se possível associar que o aumento do percentual de resíduo de madeira acelera o processo de biodegradação em solo.

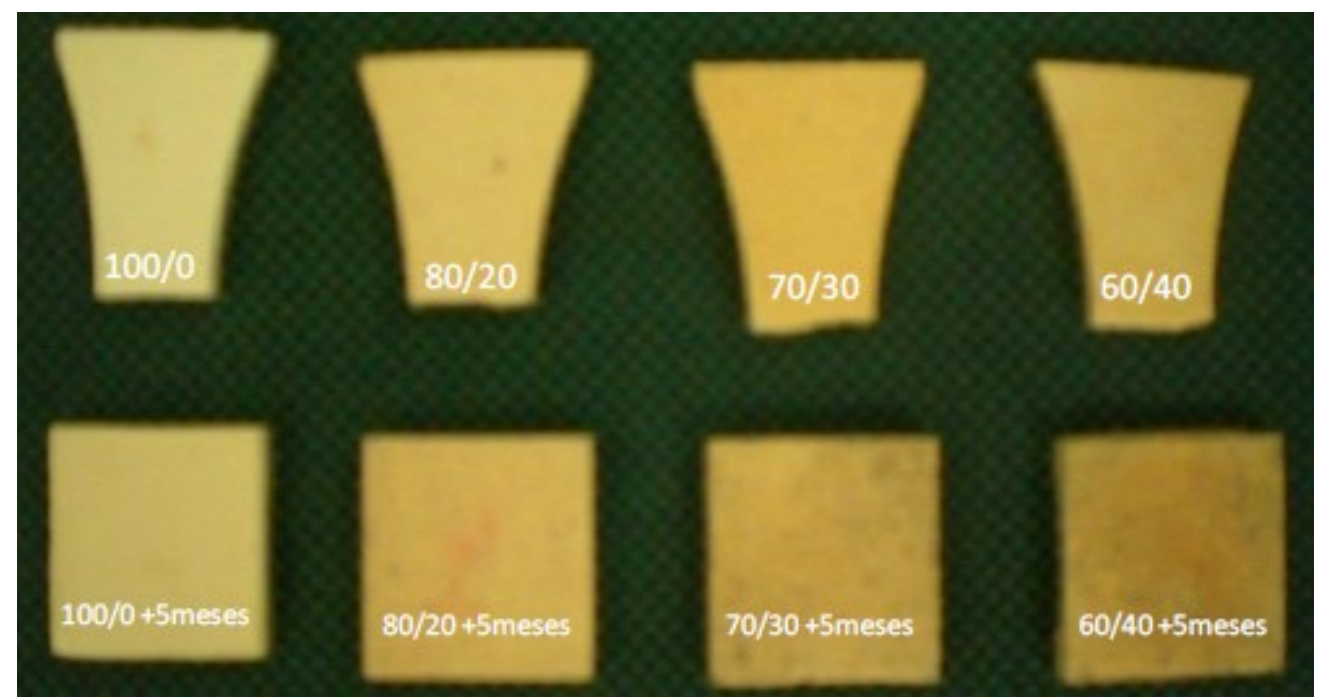

Figura 10: Análise visual dos biocompósitos PLLA/RM/MDIs após 5 meses de ensaio de biodegradação em solo.

\subsubsection{Análise termogravimétrica (TGA)}

Na Figura 11 estão mostradas as curvas TG dos biocompósitos PLLA/RM/MDI/s antes e após 5 meses de biodegradação em solo e na Tabela 5 estão relacionados os dados obtidos das curvas TG e DTG das amostras. Analisando a $\mathrm{T}_{\text {onset }}$ do PLLA após 5 meses de biodegradação em solo (Figura 11a), observa-se um aumento pronunciado de $18{ }^{\circ} \mathrm{C}$ quando comparado à amostra no tempo zero, sugerindo que o processo de degradação nestas condições ainda não tenha se iniciado. Isso pode ser confirmado por não ter sido observada nenhuma alteração visual nesta amostra. Um aumento da temperatura de início de degradação (Ti) para uma amostra de PLLA degradada em tampão fosfato também foi observado por Pezzin (2001) [55]. As amostras de PLLA com 20 e 30 \% de RM sofreram pouca alteração no perfil de degradação após 5 meses enterrada em solo (Figura 11b). Por outro lado, embora a $\mathrm{T}_{\text {onset }}$ da amostra com adição de $40 \%$ de RM não tenha se alterado, foi observado um decréscimo pronunciado da perda de massa total do PLLA que passou de 92,4 para $36,8 \%$ após 5 meses de ensaio, mostrando que o percentual de polímero da amostra caiu 55,6 \% após a biodegradação, restando um teor de resíduo lignocelulósico bem maior no final da análise até $500{ }^{\circ} \mathrm{C}$. Assim, pode-se concluir que esta amostra foi a que apresentou o processo de degradação mais acentuado, indicando que a degradação se inicia pelo polímero. 

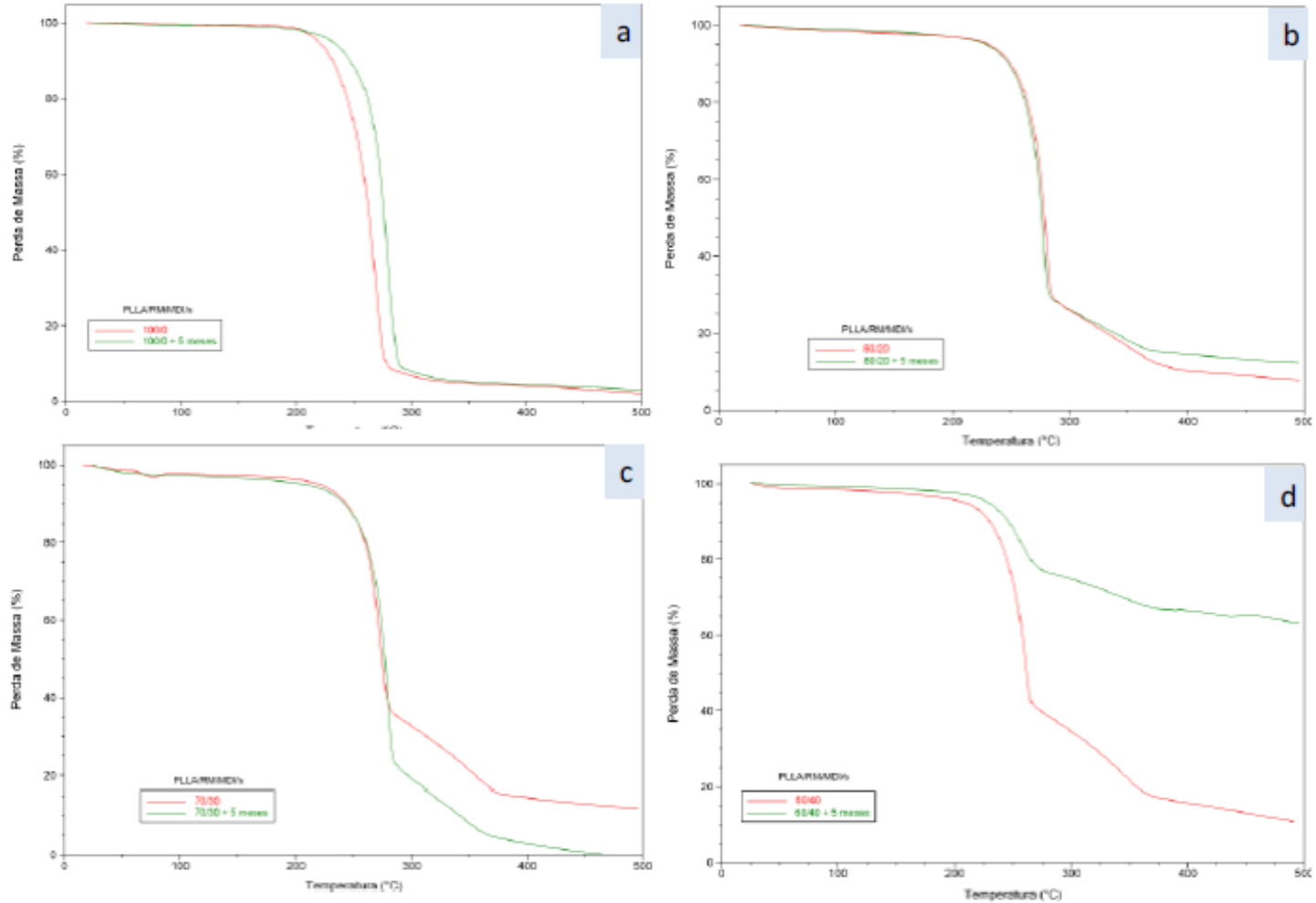

Figura 11: Curvas TG para os ensaios de biodegradação em solo dos biocompósitos PLLA/RM/MDI/s: a) 100/0, b) $80 / 20$, c) $70 / 30$, d) $60 / 40$.

Tabela 5: Dados de TGA para os biocompósitos de PLLA/RM/MDI/s antes e após 5 meses de biodegradação em solo.

\begin{tabular}{l|l|l|l}
\hline AMOSTRA & $\mathbf{T}_{\text {onset }}\left({ }^{\circ} \mathbf{C}\right)$ & $\mathbf{T}_{\text {máx }}\left({ }^{\circ} \mathbf{C}\right)$ & PERDA DE MASSA (\%) \\
\hline Antes da biodegradação & & 268 & 100 \\
\hline PLLA/RM/MDI/s 100/0 & 247 & 279 & 91,6 \\
\hline PLLA/RM/MDI/s 80/20 & 268 & 273 & 88,1 \\
\hline PLLA/RM/MDI/s 70/30 & 262 & 260 & 92,4 \\
\hline $\begin{array}{l}\text { PLLA/RM/MDI/s 60/40 } \\
\text { em solo 5ós meses de biodegradação }\end{array}$ & 245 & 279 & 97,1 \\
\hline PLLA/RM/MDI/s 100/0 & 265 & 277 & 88,2 \\
\hline PLLA/RM/MDI/s 80/20 & 266 & 278 & 100 \\
\hline \begin{tabular}{l} 
PLLA/RM/MDI/s 70/30 \\
\hline PLLA/RM/MDI/s 60/40
\end{tabular} & 266 & 260 & 36,8 \\
\hline
\end{tabular}

$\mathrm{T}_{\text {onset }}=$ temperatura de degradação e $\mathrm{T}_{\text {máx }}=$ temperatura onde a degradação é máxima 


\subsubsection{Calorimetria exploratória diferencial (DSC)}

Na Figura 12 são apresentadas as curvas de DSC dos biocompósitos antes e após o ensaio de biodegradação e na Tabela 6 estão relacionados os dados obtidos das curvas de DSC. O biocompósito 100/0, após o ensaio de biodegradação, apresentou decréscimo da $\mathrm{T}_{\mathrm{g}}$, da temperatura de cristalização $\left(\mathrm{T}_{\mathrm{c}}\right)$, da $\mathrm{T}_{\mathrm{m}}$ e do $\Delta \mathrm{H}_{\mathrm{m}}$, diminuindo consequentemente o grau de cristalinidade da amostra (que passou de 29,4 para 22,5\%). A diminuição da $T_{m}$ do PLLA em função da degradação é sinal de ocorrência de recristalização, na qual novos cristais são formados, provavelmente com menor interação entre as cadeias, que fundem a uma temperatura mais baixa. Uma diminuição da $T_{m}$ e da $T_{c}$ também foi observada por Pezzin (2001) [55] após degradação de PLLA em tampão fosfato, entretanto, houve um aumento do grau de cristalinidade. As amostras 70/30 e 60/40 apresentaram as mesmas alterações após o ensaio, sendo que a $T_{g}$ ficou muito mais pronunciada e a diminuição da $T_{c}$ foi muito maior. Estes resultados corroboram com os resultados da análise visual e termogravimétrica, de que as amostras com maior teor de resíduo estão num estágio de degradação mais avançado.

Tabela 6: Dados de DSC para os biocompósitos de PLLA/RM/MDI/s antes e após 5 meses de biodegradação em solo.

\begin{tabular}{l|l|l|l|l}
\hline AMOSTRA & $\mathbf{T}_{\mathbf{g}}\left({ }^{\circ} \mathbf{C}\right)$ & $\mathbf{T}_{\mathbf{m}}\left({ }^{\circ} \mathbf{C}\right)$ & $\Delta \mathbf{H}_{\mathbf{m}}(\mathbf{J} / \mathbf{g})$ & $\begin{array}{l}\text { PERDA DE } \\
\text { MASSA (\%) }\end{array}$ \\
\hline Antes da biodegradação & & & & \\
\hline PLLA/RM/MDI/s 100/0 & 59 & 145,150 & 31,3 & 29,4 \\
\hline PLLA/RM/MDI/s 70/30 & 56 & 143,150 & 16,3 & 15,3 \\
\hline PLLA/RM/MDI/s 60/40 & 54 & 141,151 & 18,1 & 16,9 \\
\hline $\begin{array}{l}\text { Após 5 meses de biodegradação } \\
\text { em solo }\end{array}$ & & & & \\
\hline PLLA/RM/MDI/s 100/0 & 56 & 140,150 & 24 & 22,5 \\
\hline PLLA/RM/MDI/s 70/30 & 52 & 140,149 & 21 & 19,3 \\
\hline PLLA/RM/MDI/s 60/40 & 52 & 146 & 12 & 11,3 \\
\hline
\end{tabular}


BITENCOURT, S.S.; BATISTA, K.C.; ZATTERA, A.J.; SILVA, D.A.K.; PEZZIN, A.P.T. revista Matéria, v.22, n.4, 2017.
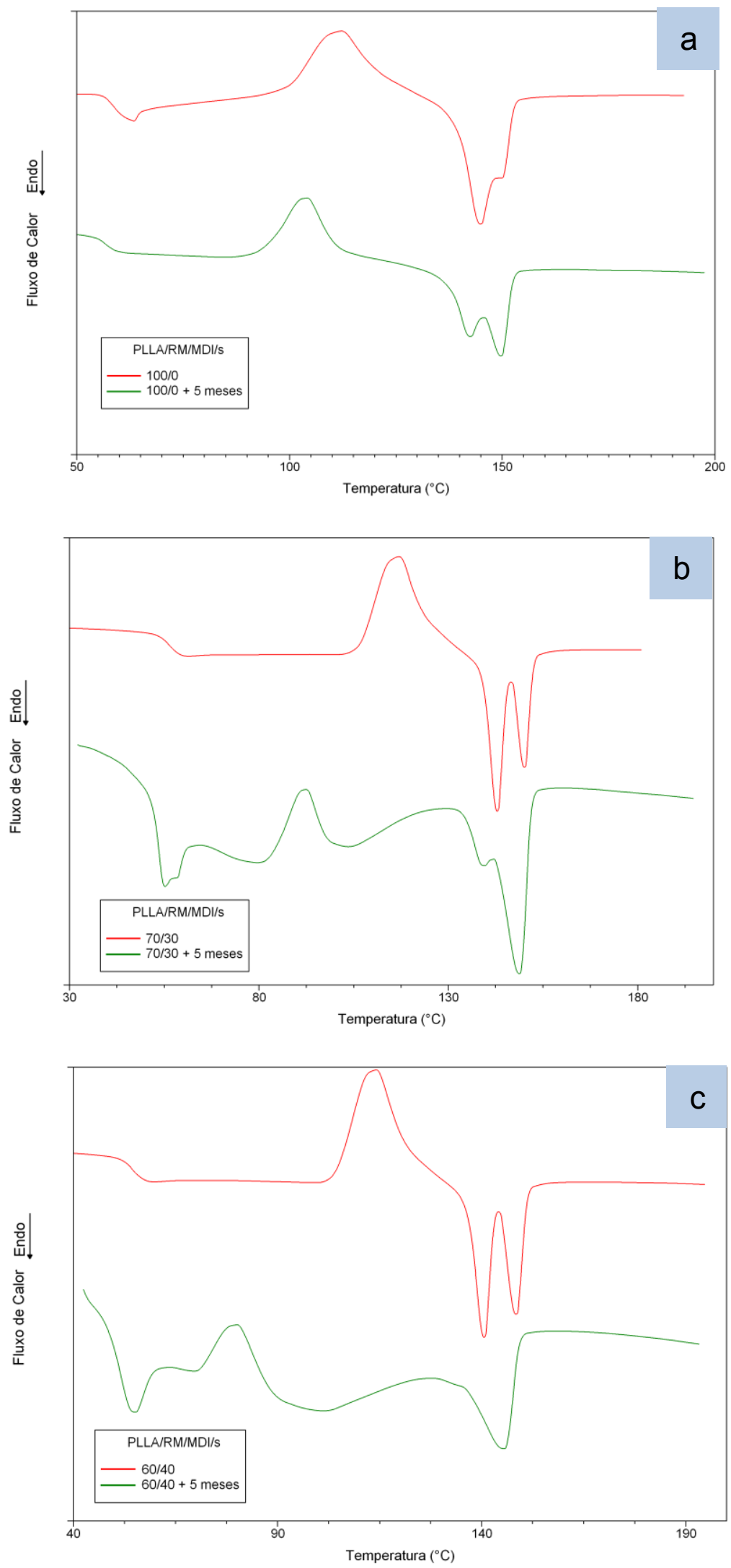

Figura 12: Curvas de DSC para os ensaios de biodegradação em solo dos biocompósitos PLLA/RM/MDI/s: a) 100/0, b) $70 / 30$, c) $60 / 40$. 


\section{CONCLUSÕES}

Neste trabalho, biocompósitos de matriz PLLA com incorporação de resíduo de madeira foram confeccionados por extrusão seguida de injeção. O efeito do MDI como promotor da adesão interfacial, bem como do agente lubrificante Struktol ${ }^{\circledR}$, nas propriedades dos biocompósitos foram investigados por diferentes técnicas.

Na presença de MDI, foi obtido um incremento de $30 \%$ na resistência à tração e de $85 \%$ no alongamento na ruptura comparando com os biocompósitos com $40 \%$ de resíduo lignocelulósico. Comparando com a adição do agente lubrificante, a resistência à tração apresentou uma queda de $66 \%$ e o alongamento na ruptura uma diminuição de $37,5 \%$. Assim, conclui-se que as propriedades mecânicas não foram favorecidas com a adição do Struktol®.

A adição de MDI nas amostras exerceu pouca influência na estabilidade térmica dos biocompósitos, enquanto o Struktol ${ }^{\circledR}$ diminuiu de forma pronunciada a estabilidade térmica tanto do polímero puro, quanto dos biocompósitos.

As micrografias de MEV revelaram que o MDI promoveu uma boa dispersão do resíduo na matriz, bem como a diminuição de vazios nas amostras com teores mais elevados de RM, promovendo uma significativa melhora na adesão interfacial resíduo/matriz, agindo como agente de acoplamento, enquanto a adição de Struktol ${ }^{\circledR}$ não alterou a morfologia.

Nas análises de FTIR das amostras com adição de MDI não se observa a banda relativa ao grupo $\mathrm{O}=\mathrm{C}=\mathrm{N}$ em nenhum dos espectros, indicando que houve reação do MDI nessas amostras. Sugere-se que o isocianato tenha reagido com os grupos hidroxilas da celulose do material vegetal com formação de grupos uretânicos e com os grupos carboxila terminais do polímero, diminuindo substancialmente a absorção de água dos biocompósitos, sem alterar a estabilidade térmica dos mesmos.

Para o PLLA sem e com a presença de MDI não ocorreu variação significativa da densidade. O biocompósito com $40 \%$ de RM apresentou um incremento na densidade de $7 \%$ quando comparado ao PLLA puro. O acréscimo de Struktol ${ }^{\circledR}$ aumentou drasticamente o percentual de teor de vazios independente do percentual de RM dos biocompósitos, o que pode justificar o baixo desempenho dessas amostras nos resultados mecânicos.

De modo geral, o aumento da concentração de RM nos biocompósitos está diretamente relacionado com o aumento de absorção de água. Entretanto, foi constatada uma diminuição de $32 \%$ na taxa de absorção de água nas amostras com MDI quando comparadas as amostras sem o uso deste aditivo, comportamento não observado nas amostras com adição de Struktol ${ }^{\circledR}$.

O ensaio de biodegradação em solo realizado com os biocompósitos com adição de Struktol@ revelou que o aumento do teor de RM acelera a biodegradação das amostras.

\section{AGRADECIMENTOS}

Ao Fundo de Apoio à Pesquisa da UNIVILLE pelo suporte financeiro e pela bolsa de S.S. Bitencourt.

\section{BIBLIOGRAFIA}

[1] SHEN, L., HAUFE, J., PATEL, M.K., Product Overview and Market Projection of Emerging Bio-based Plastics, In: Final report PRO-BIP 2009, Copernicus Institute for Sustainable Development and Innovation, Utrecht University, Utrecht, Nov., 2009.

[2] BABU, R.P., O'CONNOR, K., SEERAM, R., "Current progress on bio-based polymers and their future trends", Progress in Biomaterials, v. 2, n. 8, pp. 1-16, Mar., 2013.

[3] MURARIU, M., LAOUTID, F., DUBOIS, P., et al.,"Pathways to biodegradable flame retardant polymer (nano)composites", In: Papaspyrides, C.D., Kiliaris, P. (eds.), Polymer Green Flame Retardants, 1st ed., chapter 4, Amsterdam, Elsevier, 2014.

[4] CHEN, J., Global Markets and Technologies for Bioplastics, In: BCC Research report PLS050C, 2014.

[5] FLARIS, V., SINGH, G., "Recent developments in biopolymers", Journal of Vinyl and Additive Technology, v. 15, n. 1, pp.1-11, 2009.

[6] GANDINI, A., BELGACEM, M.N., "The state of the art of polymers from renewable resources", In: Ebnesajjad S. (ed.), Handbook of Biopolymers and Biodegradable Plastics: Properties, procession and applications, 1st ed., Boston, William Andrew Publishing, pp. 71-85, 2012.

[7] LIM, L.T., AURAS, R., RUBINO, M., "Processing technologies for poly(lactic acid)", Progress in Polymer Science, v. 33, n. 8, 820-852, Aug., 2008. 
[8] DUBOIS, P., MURARIU, M., "The "green" challenge: high performance PLA (nano)composites", JEC Composites Magazine, v. 45, pp. 66-69, 2008.

[9] MADHAVAN NAMPOOTHIRI K., NAIR, N.R., JOHN, R.P., "An overview of the recent developments in polylactide (PLA) research", Bioresource Technology, v. 101, n. 22, pp. 8493-501, Nov., 2010.

[10] KADOTA, J., PRALOVIC D., DESVERGNE, J.P., et al., "Ring- opening polymerization of 1-lactide catalyzed by an organocatalytic system combining acidic and basic sites", Macromolecules, v. 43, n. 21, pp. 8874-8879, Oct., 2010.

[11] BOURISSOU, D., MARTIN-VACA, B., DUMITRESCU, A., et al., "Controlled cationic polymerization of lactide", Macromolecules, v. 38, n. 24, pp. 9993-8, Nov., 2005.

[12] NEJATI, E., MIRZADEH, H., ZANDI, M., "Synthesis and characterization of nanohydroxyapatite rods/poly(L-lactide acid) composite scaffolds for bone tissue engineering", Composites Part A: Applied Science and Manufacturing, v. 39, n. 10, pp. 1589-1596, Oct., 2008.

[13] BIRESAW, G., CARRIERE, C.J., "Correlation between mechanical adhesion and interfacial properties of starch/biodegradable polyester blends", Journal of Polymer Science Part B: Polymer Physics, v. 39, n. 9, pp. 920-30, May, 2001.

[14] SCHMACK, G., JEHNICHEN, D., VOGEL, R., et al., "Biodegradable fibres spun from poly(lactide) generated by reactive extrusion”, Journal of Biotechnology, v. 86, n. 2, v. 151-160, Mar., 2001.

[15] HAN, H., WANG, X., WU, D., "Preparation, crystallization behaviors, and mechanical properties of biodegradable composites based on poly(L-lactic acid) and recycled carbon fiber", Composites Part A: Applied Science and Manufacturing, v. 43, n. 11, pp. 1947-1958, Nov., 2012.

[16] HAMAD, K., KASEEM, M., YANG, H.W., et al., "Properties and medical applications of polylactic acid: A review", Express Polymer Letters, v. 9, n. 5, pp. 435-455, Oct., 2015.

[17] RASAL, R.M., JANORKAR, A.V., HIRT, D.E., "Poly(lacticacid) modifications", Progress in Polymer Science, v. 35, n. 3, pp. 338-356, Mar., 2010.

[18] AURAS, R., HARTE, B., SELKE, S., "An overview of polylactides as packaging materials", Macromolecular Bioscience, v.4, n. 9, pp. 835-864, Aug., 2004.

[19] MURARIU, M., DUBOIS. P. "PLA composites: From production to properties Review", Advanced Drug Delivery Reviews, In Press, Corrected Proof, Available online 13 April 2016.

[20] MOHAMED, A., FINKENSTADT, V.L., RAYAS-DUARTE, P., et al., "Thermal properties of extruded and injection-molded poly(lactic acid)-based cuphea and lesquerella bio-composites", Journal of Applied Polymer Science, v.111, n. 1, pp. 114-124, Sep., 2009.

[21] PICKERING, K.L., SAWPAN, M.A., JAYARAMAN, J., et al., "Influence of loading rate, alkali fibre treatment and crystallinity on fracture toughness of random short hemp fibre reinforced polylactide biocomposites", Composites Part A: Applied Science and Manufacturing, v. 42, n. 9, pp. 1148-1156, May, 2011.

[22] OKSMAN, K., SKRIFVARS, M., SELIN, J.F., "Natural fibres as reinforcement in polylactic acid (PLA) composites", Composites Science and Technology, v. 63, n. 9, pp. 1317-1724, Jul., 2003.

[23] SERIZAWA, S., INOUE, K., IJI, M., "Kenaf-fiber-reinforced poly(lactic acid) used for electronic products" Journal of Applied Polymer Science, v. 100, n. 1, pp., 618-24, 2006.

[24] SINGH, S., MOHANTY, A.K., "Wood fiber reinforced bacterial bioplastic composites: Fabrication and performance evaluation”, Composites Science and Technology, v.67, pp.1753-1763, 2007.

[25] HILLING, E., SCHNEIDER, V.E., PAVONI, E.T., "Geração de resíduos de madeira e derivados da indústria moveleira em função das variáveis de produção", Produção, v.19, n. 2, pp. 292-303, Mai-Ago, 2009.

[26] FONTES, P.J.P. Auto-suficiência energética em serraria de Pinus e aproveitamento dos resíduos, Dissertação de M.Sc., FEF/UFPR, Curitiba, SC, Brasil, 1994.

[27] LUO, S., NETRAVALI, A.N., "Interfacial and mechanical properties of environment- friendly "green" composites made from pineapple fibers and poly(hydroxybutyrate-co-valerate) resin", Materials Science, v.34, n.15, pp. 3709-3719, Aug., 1999.

[28] TERAMOTO, N., URATA, K., OZAWA, K., et al., "Biodegradation of aliphatic polyester composites reinforced by abacá fiber", Polymer Degradation and Stability, v.86, n. 3, pp.401-409, Dec., 2004. 
[29] BENGTSSON, M., OKSMAN, K., "The use of silane technology in crosslinking polyethylene/wood flour composites", Composites Part A: Applied Science and Manufacturing, v.37, n. 5, pp.752-765, May., 2006.

[30] COUTINHO, F.M.B., COSTA, T.H.S., "Performance of polypropylene-wood fiber composites", Polymer Testing, v.18, n. 8, pp. 581-587, Dec., 1999.

[31] CORREA, C.A., FONSECA, C.N.P., NEVES, S., et al., "Compósitos Termoplásticos com Madeira", Polímeros: Ciência e Tecnologia, v.13, n. 3, p.154-165, 2003.

[32] CHIANG, W.Y., YANG, W.D., "Polypropylene Composites I: Studies of the effects of grafting of acrylic acid and silane coupling agent on the performance of polypropylene mica composites", Journal of Applied Polymer Science, v. 35, n. 3, pp. 807-823, Feb., 1988.

[33] CHELAK, W., NEWMAN, W.H., "MDI high moisture content bonding mechanism, parameter, and benefits using MDI in composite wood products", In: Proceedings of 25th International Symposium of Washington State University on Particleboard/Composite Materials, Washington, pp.205-229, 1991.

[34] GAO, Z.H., GU, F.Y., WANG, X.M., et al., "FTIR and XPS study of the reaction of phenyl isocyanate and cellulose with different moisture contents", Pigment \& Resin Technology, v. 34, n. 5, pp. 282-289, 2005.

[35] YU, L., PETINAKIS, S., DEAN, K., et al., "Green Polymeric Blends and Composites from Renewable Resources", Macromolecular Symposia. Special Issue: Advanced Polymer for Emerging Technologies, v. 249-251, n. 1, pp. 535-539, Mar., 2007.

[36] BATISTA, K. C., SILVA, D.A.K., COELHO, L.A.F., et al., "Soil biodegradation of PHBV/peach palm particles biocomposites", Journal of Polymers and the Environment, v. 18, n. 3, pp. 346-354, Sep., 2010.

[37] BAX, B., MÜSSIG, J., "Impact and tensile properties of PLA/Cordenka and PLA/flax composites", Composite Science and Technology, v. 68, n. 7-8, pp. 1601-1607, Jun., 2008.

[38] HUDA, M.S., DRZAL, L.T., MOHANTY, A.K., et al., "Wood fiber reinforced poly(lactic-acid) composites" In: Proceedings of 5th Annual SPE Automotive Composite Conference (ACCE), Michigan, 2005.

[39] GRAUPNER, N., HERMANN, A.S., MÜSSIG, J., "Natural and man-made cellulose fibrereinforced poly(lactic acid) (PLA) composites: An overview about mechanical characteristics and application areas", Composites Part A: Applyed Science Manufacture, v. 40, n. 6-7, pp. 810-821, Jul., 2009.

[40] OKUBO, K., FUJII, T., THOSTENSON, E.T., "Multi-scale hybrid biocomposite: Processing and mechanical characterization of bamboo fiber reinforced PLA with microfibrillated cellulose", Composites: Part A: Applyed Science Manufacture, v.40, n. 4, pp.469-475, Apr., 2009.

[41] CHENG, S., LAU, K., LIU, T., et al., "Mechanical and thermal properties of chicken feather fiber/PLA green composites", Composites Part B: Engineering, v. 40, n. 7, pp. 650-654, Oct., 2009.

[42] ASTM D-618-13. Standard Practice for Conditioning Plastics for Testing, 2013.

[43] ISO 527-1:2012. Plastics - Determination of tensile properties - Part 1: General principles, 2012.

[44] ASTM D-638-14. Standard Test Method for Tensile Properties of Plastics, 2014.

[45] ASTM D-570-98(2010)e1. Standard Test Method for Water Absorption of Plastics, 2010.

[46] ASTM D-2734-16. Standard Test Methods for Void Content of Reinforced Plastics, 2016.

[47] ASTM G160-98. Standard Practice for Evaluating Microbial Susceptibility of Nonmetallic Materials by Laboratory Soil Burial, 1998.

[48] PLACKETT, D., ANDERSEN, T.L., PEDERSEN, W.B., et al., "Biodegradable composites based on Lpolylactide and jute fibres", Composites Science and Technology. v. 63, n. 9, pp.1287-1296, Jul, 2003.

[49] WANG, H., SUN, X., SEIB, P., "Strengthening blends of poly(lactic acid) and starch with methylenediphenyl diisocyanate", Journal of Applied Polymer Science, v. 82, n. 7, pp. 1761-1767, Nov., 2001.

[50] SMITH, W.F., Princípios de Ciência e Engenharia de Materiais, 3 ed., Portugal, McGraw-Hill Ltda, 1998.

[51] SILVA, V.D., BATISTA, K.C., ZATTERA, A.J., et al., "Poly(3-hydroxybutyrate-co-3-

hydroxyvalerate)/wood powder biocomposites: Thermal and mechanical properties and water absorption profile", Journal of Reinforced Plastics and Composites, v. 33, pp. 741-748, 2014.

[52] HUDA, M.S., DRZAL, L.T., MOHANTY, A.K., et al., "Chopped glass and recycled newspaper as reinforcement fibers in injection molded poly(lactic acid) (PLA) composites: A comparative study", Composites Science and Technology, v. 66, n. 11-12, pp.1813-1824, Sep., 2006. 
[53] SILVERSTEIN, R.M., WEBSTER, F.X. Identificação espectrométrica de compostos orgânicos, 6 ed., Rio de Janeiro, LTC - Livros Técnicos e Científicos Editora S.A., 2000.

[54] DRUMOND, W.S., MOTHE, C.G., WANG,S.H. "Síntese e caracterização do copolímero poli(ácido láctico-b-glicol etilênico)", Polímeros: Ciência e Tecnologia, v.14, n. 2, pp.74-79, 2004.

[55] PEZZIN, A.P.T. Obtenção e caracterização de blendas de poli(p-dioxanona)/poli (L-ácido láctico) (PPD/PLLA) para aplicação como prótese de menisco bioreabsorvível., Tese de D.Sc., FEM/UNICAMP, Campinas, SP, Brasil, 2001. 